\title{
Long-term trends of oxygen concentration in the waters in bank and shelves of the Southern Japan Sea
}

\author{
Tsuneo Ono ${ }^{1}$
}

Received: 31 October 2020 / Revised: 15 February 2021 / Accepted: 19 February 2021 / Published online: 15 March 2021

(c) The Author(s) 2021

\begin{abstract}
While multiple studies have investigated oxygen decrease in Japan Sea Proper Water (JSPW; > $300 \mathrm{~m}$ in depth), oxygen variation in continental slope and shelf waters $(<300 \mathrm{~m})$ must also be investigated in order to assess its socioecological impacts. In this study, historical oxygen data in the waters of three continental shelves and a bank of Japan Sea, off-Awashima area (AW), Wakasa Bay (WB), East of Tsushima Straight (ETS), and Yamato Bank (YB), were collected and analyzed to assess temporal variation of oxygen in each region from 1960 to 2000s. Significant decreasing trends of oxygen were detected in the waters below $150 \mathrm{~m}$ depth in $\mathrm{WB}$ and $\mathrm{YB}$, and below $300 \mathrm{~m}$ in $\mathrm{AW}$, in the summer season. In winter, a decreasing trend of oxygen was detected throughout the water column from $300 \mathrm{~m}$ to the sea surface in WB and YB. In ETS, a deoxygenation trend was detected throughout the water column from the bottom to the sea surface in the summer season, while no trend was detected in winter. The results suggested that oxygen decreases in AW, WB, and YB were the consequence of the upward propagation of the deoxygenation signal from JSPW, while that of ETS was caused by horizontal propagation of deoxygenation signal from the East China Sea. Assuming that the observed trend will continue in future, it is predicted that part of the water in Tsushima Strait area will reach the general sublethal threshold of oxygen $\left(134 \mu \mathrm{mol} \mathrm{kg}{ }^{-1}\right)$ by the end of this century.
\end{abstract}

Keywords Deoxygenation · Japan Sea $\cdot$ Continental Shelves · Yamato Bank · Global Warming

\section{Introduction}

There are growing concerns about oxygen declines that are now being detected in oceans worldwide, oceanic subsurface, and coastal regimes (e.g., Helm et al. 2011; IPCC 2013, 2019; Ito et al. 2017; Koslow et al. 2011, 2015; Oschlies et al. 2018; Sasano et al. 2015, 2018; Schmidtko 2017; Stramma et al. 2010, 2011, 2012, 2020; Rabalais et al. 2010; Whitney et al. 2013; Zhang et al. 2010). The Japan Sea is known as a one of key spot of ocean deoxygenation, where oxygen concentration has dramatically decreased in the waters below a depth of 300 m (i.e., Japan Sea Proper Water, hereafter JSPW) since no later than 1950s (e.g., Chen, 1999; Gamo 1999, 2011; Gamo et al. 1986, 2001, 2014; Minami et al. 1999; Watanabe et al. 2003). These phenomena are attributed to the result of diminished deep-water

Tsuneo Ono

tono@fra.affrc.go.jp

1 Marine Environment Division, Fisheries Resources Institute, Japan Fisheries Research and Education Agency, Yokohama, Japan convection, which itself was caused by warming of winter surface water of the northern Japan Sea. Although recent observations indicated that the formation of Japan Sea Bottom Water had revived intermittently since the 2000s (e.g., Talley et al. 2003; Tsunogai et al. 2003), the overall trend of oxygen decrease in JSPW was maintained until at least 2010.

However, little were argued about temporal variation of oxygen in the waters above JSPW, ca, shallower than $300 \mathrm{~m}$ depth. Although several observations (e.g., Chen et al. 2017) indicate that oxygen concentration should have been decreased even in the waters shallower than $300 \mathrm{~m}$, large horizontal variation of historical oxygen data in these shallow depth ranges prevents detailed analyses at the basin scale. However, the number of animal species in the Japan Sea is far richer in the continental-shelf region than in the deep-water region (e.g., Nishimura 1968). Fisheries communities also use continental-shelf regions as well as deep water regions, catching continental-shelf peculiar fish composition that cannot be obtained from deep-water regions (Nishimura 1966). The temporal change in oxygen content in shallow waters, especially those in continental-shelf areas, 
is even more important than that of deep waters when considering its socioeconomic impact.

In this study, the long-term trend of oxygen concentration in shallow waters of the bank and continental shelves of southern Japan Sea was investigated using historical hydrographic data collected from the 1960s. Geographical variations in oxygen trends, possible causes, and their impacts on ocean ecosystems will be presented and discussed.

\section{Data and method}

At first, historical ocean station data (OSD) containing water temperature, salinity and oxygen concentration were extracted from the World Ocean Database 2018 (Boyer et al. 2018), as observed in three continental shelves and one bank of the southern Japan Sea as follows: Yamato Bank (YB), $133^{\circ} \mathrm{E}-137^{\circ} \mathrm{E}$ and $38.5^{\circ} \mathrm{N}-40.5^{\circ} \mathrm{N}$; offAwashima area (AW), $138^{\circ} \mathrm{E}-140^{\circ} \mathrm{E}$ and $38.25^{\circ} \mathrm{N}-40^{\circ} \mathrm{N}$; Wakasa Bay (WB), $135^{\circ} \mathrm{E}-136^{\circ} \mathrm{E}$ and $35.5^{\circ} \mathrm{N}-36.5^{\circ} \mathrm{N}$; and the east of the Tsushima Straight (ETS), $130^{\circ} \mathrm{E}-132.5^{\circ}$ $\mathrm{E}$ and $34^{\circ} \mathrm{N}-35.5^{\circ} \mathrm{N}$. These four regions were selected for this study based on the following criteria: (1) continental shelves and/or banks with enough size of area, and (2) having a suitable amount of historical oxygen data with time length over a period of 30 years. In each region, data from the summer (July to September) and winter (December to February) seasons for 1960s-2000s were collected and analyzed separately to avoid potential effects of seasonal variation. Unfortunately, the winter data of AW had substantial interruptions for 1976-1998; therefore, only summer data were analyzed for this site. Data for six reference depth ranges $(0-1 \mathrm{~m}, 50 \pm 3 \mathrm{~m}, 100 \pm 5 \mathrm{~m}, 150 \pm 5 \mathrm{~m}$, $200 \pm 5 \mathrm{~m}, 300 \pm 5 \mathrm{~m}$ ) were then extracted. After that, data in each region were inspected by the following two-step data selection.
As the first step, horizontal distribution of water temperature, salinity and dissolved oxygen within each region were examined on each depth ranges. Then, geographic area adopted for the further analysis in each region were narrowed down so that all three parameters show homogeneous horizontal distribution within that region (see Appendix 1). We made this selection, so that we can avoid any affection of year-to-year difference of geographic distribution of hydrographic stations. As this result, latitudinal and longitudinal ranges of the four regions were changed as shown in Table 1 (also See Fig. 1). Range of years collected in each study area is also listed in the table. The oldest data were obtained during the years of 1965-1968 in all regions, but availability of the latest oxygen data varies from 1999 in ETS to 2005-2008 in YB, AW, and WB.

As the second step, standard deviation (SD) of each parameter (water temperature, salinity and oxygen concentration) was calculated in terms of depth range and season for each of the four study areas. Data outside of the range of $3 \times \mathrm{SD}$ were then omitted to avoid analytical errors and/ or episodic events, such as extremely high precipitation. Once any parameter of a water sample was omitted, the corresponding data of all other parameters for that same sample were automatically omitted. This omission process was repeated twice. Number of stations extracted from WOD2018 was 2663 at first, and from these ones, 1465 stations were remained after the first step selection. After the second step data selection, 1291 stations containing 10,819 data $(3607,3607$, and 3605 for oxygen, water temperature, and salinity, respectively) were finally remained and were used for time series analysis (Table 1). Solubility of oxygen at $1 \mathrm{~atm}$ pressure $\left(\mathrm{DO}_{\mathrm{sol}}\right)$ were additionally calculated from water temperature and salinity by using the equation of Weiss (1970), and were also used for time series analysis.
Table 1 Metadata of each study area. Not all stations achieved fullcast observations to bottom depth; therefore, a number of data in deeper depth ranges are smaller than those described in this table. As a result, analyses on certain depth ranges could not be carried out for WB and ETS due to large interruptions of their time series

\begin{tabular}{|c|c|c|c|c|c|c|}
\hline $\begin{array}{l}\text { Name of Study } \\
\text { Area }\end{array}$ & $\begin{array}{l}\text { Longitu-dinal } \\
\text { Range }\end{array}$ & Latitudi-nal Range & Bottom depth [m] & $\begin{array}{l}\text { Deepest Depth } \\
\text { Analyzed [m] }\end{array}$ & Number of Stations & Time Coverage \\
\hline $\begin{array}{l}\text { East of the Tsush- } \\
\text { ima Strait (ETS) }\end{array}$ & $130^{0} \mathrm{E}-132.5^{0} \mathrm{E}$ & $34^{0} \mathrm{~N}-35.5^{0} \mathrm{~N}$ & $<200 \mathrm{~m}$ & 100 & $\begin{array}{l}\text { Summer: } 398 \text { Win- } \\
\text { ter: } 229\end{array}$ & $\begin{array}{l}\text { Summer: 1965-1999 } \\
\text { Winter: 1967-1999 }\end{array}$ \\
\hline Wakasa Bay (WB) & $135.25^{0} \mathrm{E}-136^{0} \mathrm{E}$ & $35.6^{0} \mathrm{~N}-36.25^{0} \mathrm{~N}$ & $<300 \mathrm{~m}$ & 200 & $\begin{array}{l}\text { Summer: } 161 \text { Win- } \\
\text { ter: } 113\end{array}$ & $\begin{array}{r}\text { Summer: } 1968-2007 \\
\text { Winter: 1965-2008 }\end{array}$ \\
\hline $\begin{array}{l}\text { Awashima area } \\
\text { (AW) }\end{array}$ & $138^{0} \mathrm{E}-139.5^{0} \mathrm{E}$ & $38.25^{0} \mathrm{~N}-40^{0} \mathrm{~N}$ & $150 m-3000 m$ & 300 & $\begin{array}{l}\text { Summer: } 96 \text { Win- } \\
\text { ter: None }\end{array}$ & $\begin{array}{l}\text { Summer: } 1965-2005 \\
\text { Winter: None }\end{array}$ \\
\hline Yamato Bank (YB) & $134^{0} \mathrm{E}-136^{0} \mathrm{E}$ & $38.5^{0} \mathrm{~N}-39.25^{0} \mathrm{~N}$ & $236 m-3000 m$ & 600 & $\begin{array}{l}\text { Summer: } 175 \text { Win- } \\
\text { ter: } 119\end{array}$ & $\begin{array}{r}\text { Summer: } 1965-2007 \\
\text { Winter: 1966-2008 }\end{array}$ \\
\hline
\end{tabular}


Fig. 1 Map of data extracted for this study. Ocean Data View 4 software (Schlitzer 2013) was used to draw this map. Topography is overlaid by color scale. Blue dots indicate stations firstly extracted from WOD 2018, while the black dashed line boxes denote area finally used for the analysis after the horizontal homogeneity assessment described in Appendix 1. The brown dashed line box denotes area of WTS described in Sect. 4.2

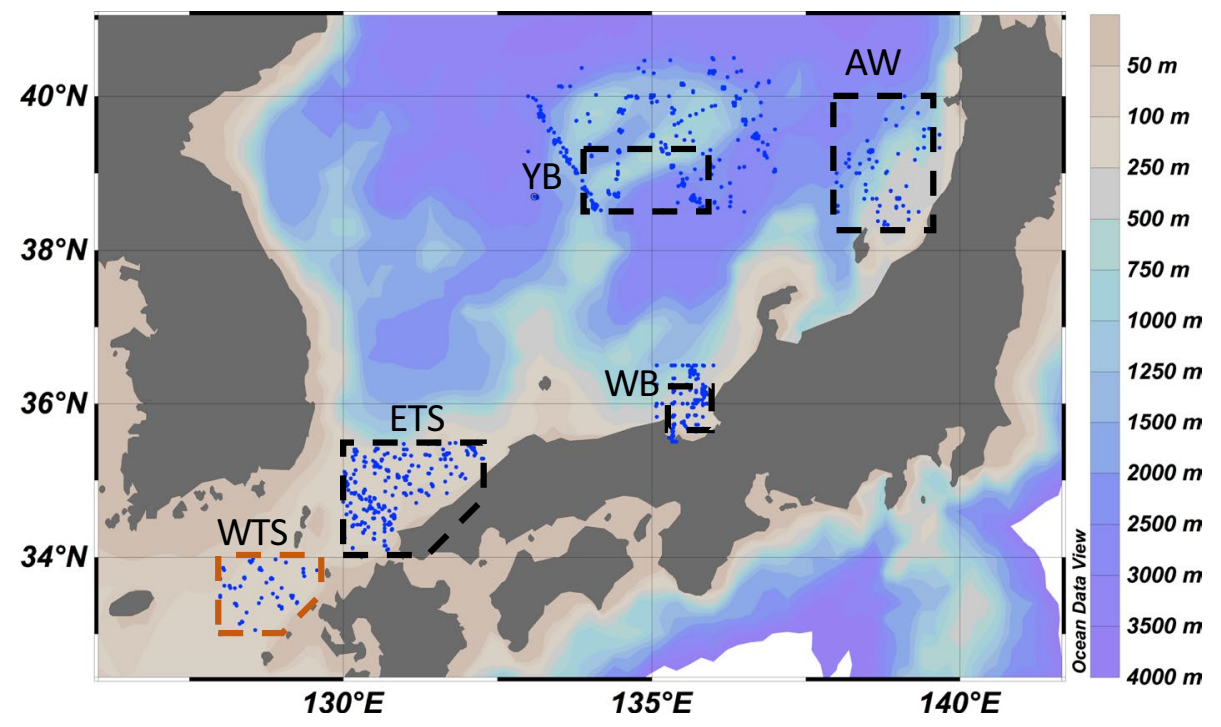

\section{Results}

Figure 2 shows an example time series of water temperature, salinity, and oxygen observed in $0-1 \mathrm{~m}$ depth range of YB in winter. Time series plot of oxygen for all isobaths, seasons and areas are further shown in Appendix 2.

Watanabe et al. (2003) estimated that the analytical uncertainty of historical oxygen data in Japan Sea was less than $5 \mu \mathrm{mol} \mathrm{kg}{ }^{-1}$, but the typical standard variation of oxygen obtained from a single-year time slice of Fig. 2 was $10 \mu \mathrm{mol} \mathrm{kg}{ }^{-1}$. This indicates that part of variations of oxygen those are caused by the factors other than the long-term variation (e.g., geographical variations, tides, weathers and intra-seasonal variations within the 3-month window) were still remained even after the data selection process. Water temperature and salinity also showed single-year standard deviation $\left( \pm 1.5^{\circ} \mathrm{C}\right.$ and \pm 0.05 for water temperature and salinity, respectively) that were far larger than the expected analytical uncertainty $\left( \pm 0.002{ }^{\circ} \mathrm{C}\right.$ and \pm 0.002 for water temperature and salinity, Joyce 1991). The observed time series further showed several episodic year-to-year variation indicating the existence of short-term variation of each property in this depth range of winter YB. Nevertheless, we can obtain significant linear decrease of oxygen at the rate of $-0.50 \pm 0.12 \mu \mathrm{mol} \mathrm{kg}{ }^{-1} \cdot \mathrm{y}^{-1}$ sustaining the whole time period, as well as linear increase of water temperature $\left(0.08 \pm 0.02{ }^{\circ} \mathrm{C} \cdot \mathrm{y}^{-1}\right)$ and weak decreasing of salinity $\left(-0.002 \pm 0.01 \cdot y^{-1}\right)$. Similarly, linear long-term change (e.g., trend) of each parameter that was statistically significant even under the existence of short-term variation was observed in many time series with various depth ranges, areas, and seasons (Appendix 2). Linear trend of each parameter (water temperature, salinity, oxygen concentration and $\mathrm{DO}_{\mathrm{sol}}$ ) over the whole period was calculated for each depth range in each region, and are listed in Tables 2 and 3 for summer and winter data, respectively.

We additionally calculated 10-year average of each parameter for the time period of 1965-1974, 1975-1984, 1985-1994, and 1995-2004, for each isobaths in each region (however, the average of 1995-2004 was not calculated for ETS as only the data before 1999 was collected in this region). Vertical profiles of each parameter typical for each time period were then illustrated in Fig. 3.

\subsection{Yamato Bank}

Vertical profiles of oxygen in this region in summer season was characterized by a broad subsurface maximum located from 150 to $300 \mathrm{~m}$ (Fig. 3c). This corresponds to the Japan Sea Intermediate Water (JIW), the watermass characterized by relatively low salinity and high oxygen concentration bordering JSPW at around $300 \mathrm{~m}$ (Senjyu 1999). Significant negative trend of oxygen was observed in JIW (isobaths of $150 \mathrm{~m}$ and $200 \mathrm{~m}$, Fig. 10d, e in Appendix 2) and upper JSPW (300 m isobaths, Fig. 10 in Appendix 2). Although JIW was characterized by its low salinity, no trend was observed in salinity within this depth range (Tables 2 and 3), indicating that the volume of JIW has not changed significantly during this period. Water temperature showed significant decrease after 1975 on the isobaths from 50 to $300 \mathrm{~m}$ in summer season (Fig. 3a), and as this result, $\mathrm{DO}_{\text {sol }}$ has been increased on these isobaths (Table 2). In winter, both water temperature and $\mathrm{DO}_{\text {sol }}$ showed no significant trend on the isobaths from 100 to $300 \mathrm{~m}$ (Table 3). 

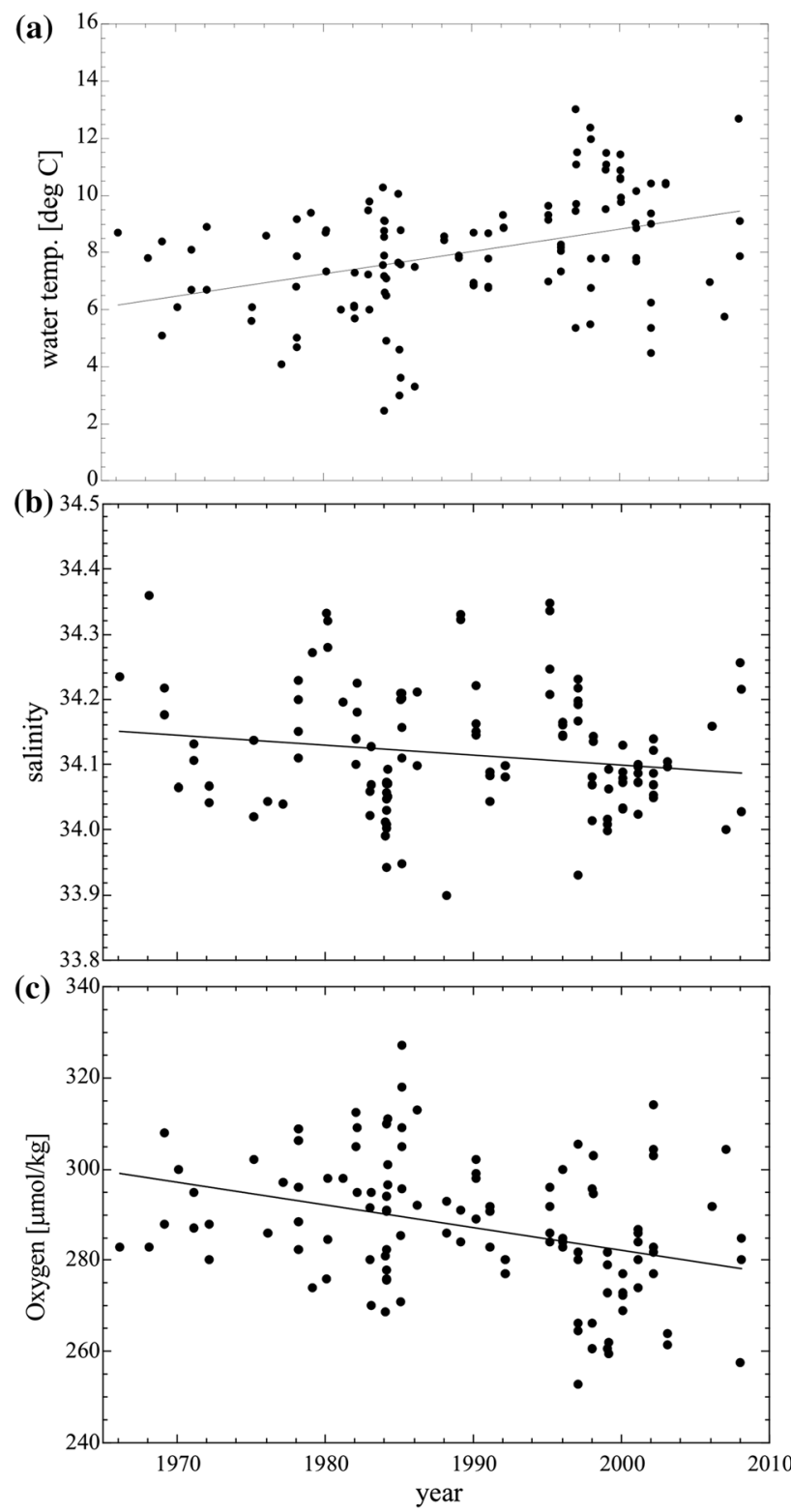

Fig. 2 Example time series of water temperature, salinity, and dissolved oxygen observed in $0-1 \mathrm{~m}$ of $\mathrm{YB}$ in winter

The observed negative trend of oxygen in JIW is, therefore, not explained by the change in the solubility of oxygen at the source water of the JIW.

In wither, mixed layer was developed to the depth of $100 \mathrm{~m}$ in this region (Fig. 3a). Oxygen concentration of these waters are generally equal to $\mathrm{DO}_{\text {sol }}$ (data not shown), indicating that the waters were well saturated with oxygen all through the period. The absolute concentration of oxygen in the winter mixed layer; however, largely decreased after 1995 (Fig. 3c). This was due to the decrease of $\mathrm{DO}_{\text {sol }}$ caused by the rapid warming of winter surface water (Fig. 3a). As this result, oxygen and $\mathrm{DO}_{\text {sol }}$ showed negative trend in the top three reference depth ranges in winter (Table 3, Fig. 10g-i in Appendix 2). JIW remained below the winter mixed layer (Fig. 3a, b), and negative trend of oxygen were still observed in JIW and upper JSPW (150 m and 300 m, Table 3, Fig. 10hj, 1 in Appendix 2). In 200 m, statistical significance of negative oxygen trend became week, but sign of the calculated oxygen trend was still negative. As this result, oxygen showed negative trend in the whole water column from surface to $300 \mathrm{~m}$ in winter.

\subsection{Off-Awashima Area}

Here, two peaks were observed in oxygen profiles (Fig. 3f). The upper one (peak depth $50 \mathrm{~m}$ ) was attributed to the subsurface oxygen maximum produced by the photosynthesis just above the subsurface chlorophyll maximum (Kodama et al. 2015; Kim et al. 2019). The lower one (peak depth $200 \mathrm{~m}$ ) was attributed to JIW, with its thickness becomes smaller when compared to that in summer YB (Fig. 3c). Oxygen concentration showed negative trend in upper JSPW (300 m, Fig. 11f in Appendix 2) similar to YB. Negative trend of oxygen was also calculated in JIW (150 m and $200 \mathrm{~m}$, Fig. 11d, e in Appendix 2), although its statistical significance was lost in AW probably due to the small data numbers as compared to YB.

A positive oxygen trend was observed in three reference depth ranges containing the upper oxygen peak ( $0-1 \mathrm{~m}$ and $100 \pm 5$ m, Fig. 11a, c in Appendix 2, Table 2). Significant cooling was observed in these waters (Table 2), and as this result, $\mathrm{DO}_{\text {sol }}$ had been increased on these reference depth ranges at almost the same rate with those of oxygen (Table 2). Although the shape of the upper oxygen peak is maintained by the biological processes, the present result indicated that the temporal variation of oxygen concentration in this depth range was controlled not by the biological process, but by the temporal variation of water temperature.

\subsection{Wakasa Bay}

This region also showed double oxygen peak in summer season (Fig. 3i), and source of each peak was same as that of AW. Figures 12a, b in Appendix 2 indicated that the oxygen concentration in summer season had been increased on the upper two reference depth ranges (0-1 m, 50 $3 \mathrm{~m})$, but these signals were not statistically significant (Table 2) because year-to-year variations of oxygen concentration were very large on these isobaths. As this region locates 
Table 2 Trends of water temperature (Temp), salinity (Sal), dissolved oxygen (DO), and solubility of oxygen $\left(\mathrm{DO}_{\text {sol }}\right)$ in each reference depth range in each study area (summer data).

\begin{tabular}{|c|c|c|c|c|}
\hline Depth Range & ETS & WB & AW & YB \\
\hline \multicolumn{5}{|l|}{$[0-1 \mathrm{~m}]$} \\
\hline Temp & $-0.01 \pm 0.01$ & $0.00 \pm 0.01$ & $-0.06 \pm 0.02$ & $-0.02 \pm 0.02$ \\
\hline Sal & $-0.003 \pm 0.004$ & $0.006 \pm 0.005$ & $0.006 \pm 0.003$ & $0.004 \pm 0.002$ \\
\hline DO & $-0.19 \pm 0.08^{\#}$ & $0.07 \pm 0.07$ & $0.32 \pm 0.08$ & $0.15 \pm 0.09$ \\
\hline $\begin{array}{l}\mathrm{DO}_{\text {sol }} \\
{[50 \pm 3 \mathrm{~m}]}\end{array}$ & $0.03 \pm 0.04$ & $-0.01 \pm 0.06$ & $0.20 \pm 0.06$ & $0.08 \pm 0.06$ \\
\hline Temp & $-0.01 \pm 0.01$ & $-0.04 \pm 0.03$ & $-0.13 \pm 0.04$ & $-0.10 \pm 0.04$ \\
\hline Sal & $0.001 \pm 0.002$ & $0.002 \pm 0.004$ & $0.002 \pm 0.002$ & $-0.003 \pm 0.002$ \\
\hline DO & $-0.70 \pm 0.10^{\#}$ & $0.03 \pm 0.24$ & $0.57 \pm 0.34$ & $-0.12 \pm 0.36$ \\
\hline $\begin{array}{l}\mathrm{DO}_{\text {sol }} \\
{[100 \pm 5 \mathrm{~m}]}\end{array}$ & $0.06 \pm 0.06$ & $0.18 \pm 0.12$ & $0.69 \pm 0.22$ & $0.56 \pm 0.21$ \\
\hline Temp & $-0.01 \pm 0.01$ & $-0.01 \pm 0.03$ & $-0.11 \pm 0.04$ & $-0.06 \pm 0.04$ \\
\hline Sal & $-0.002 \pm 0.001$ & $0.000 \pm 0.002$ & $-0.003 \pm 0.002$ & $-0.002 \pm 0.002$ \\
\hline DO & $-0.31 \pm 0.10^{\#}$ & $-0.16 \pm 0.25$ & $0.38 \pm 0.19$ & $-0.07 \pm 0.18$ \\
\hline $\begin{array}{l}\mathrm{DO}_{\text {sol }} \\
{[150 \pm 5 \mathrm{~m}]}\end{array}$ & $0.04 \pm 0.06$ & $0.03 \pm 0.14$ & $0.70 \pm 0.27$ & $0.45 \pm 0.26$ \\
\hline Temp & & $0.00 \pm 0.03$ & $0.10 \pm 0.07$ & $-0.05 \pm 0.03$ \\
\hline Sal & & $-0.001 \pm 0.002$ & $0.008 \pm 0.002$ & $0.000 \pm 0.001$ \\
\hline DO & & $-0.29 \pm 0.14^{\#}$ & $-0.16 \pm 0.16$ & $-0.30 \pm 0.14^{\#}$ \\
\hline $\begin{array}{l}\mathrm{DO}_{\text {sol }} \\
{[200 \pm 5 \mathrm{~m}]}\end{array}$ & & $0.00 \pm 0.19$ & $-0.66 \pm 0.46$ & $0.42 \pm 0.25$ \\
\hline Temp & & $-0.02 \pm 0.02$ & $-0.04 \pm 0.04$ & $-0.06 \pm 0.03$ \\
\hline Sal & & $-0.001 \pm 0.001$ & $0.001 \pm 0.001$ & $-0.001 \pm 0.001$ \\
\hline DO & & $-0.67 \pm 0.19^{\#}$ & $-0.16 \pm 0.15^{\#}$ & $-0.46 \pm 0.21^{\#}$ \\
\hline $\begin{array}{l}\mathrm{DO}_{\text {sol }} \\
{[300 \pm 5 \mathrm{~m}]}\end{array}$ & & $0.14 \pm 0.16$ & $0.37 \pm 0.35$ & $0.47 \pm 0.23$ \\
\hline Temp & & & $-0.01 \pm 0.01$ & $-0.02 \pm 0.01$ \\
\hline Sal & & & $0.001 \pm 0.001$ & $0.000 \pm 0.000$ \\
\hline DO & & & $-0.80 \pm 0.30^{\#}$ & $-0.62 \pm 0.27^{\#}$ \\
\hline $\mathrm{DO}_{\text {sol }}$ & & & $0.13 \pm 0.08$ & $0.19 \pm 0.13$ \\
\hline
\end{tabular}

Units are ${ }^{\circ} \mathrm{C} \cdot \mathrm{y}^{-1}, \mathrm{y}^{-1}$, and $\mu \mathrm{mol} \mathrm{kg} \mathrm{kg}^{-1} \cdot \mathrm{y}^{-1}$ for Temp, Sal, DO and $\mathrm{DO}_{\text {sol }}$, respectively. The plus-minus value represents 1SD. Bold font indicates the trends which have statistical significance with $p$ value less than 0.05 . Superscripts \# represents signs of the trends were not changed among $\mathrm{TR}_{\text {full }}, \mathrm{TR}_{\text {-last 10 }}$, and $\mathrm{TR}_{\text {-first10 }}$ at the observation-period sensitivity test (Appendix 3) coastal side of the boundary current (First Branch of Tsushima Warm Current, FBTWC), coastal processes, such as patchy biological activities in the upper water column may generate such short time variability of the oxygen in this region. On the other hand, negative signal of oxygen in JIW (150 $\pm 5 \mathrm{~m}$ and $200 \pm 5 \mathrm{~m})$ were still statistically significant even in this coastal region (Table 2, Fig. 12d, e in Appendix 2). Note that the rate of oxygen decreases in the reference depth range of $200 \pm 5 \mathrm{~m}(-0.67 \pm 0.19 \mu \mathrm{mol}$ $\mathrm{kg}^{-1} \cdot \mathrm{y}^{-1}$, Table 2) was far larger than those observed in YB and $\mathrm{AW}$ on the same depth range, but this high rate was mainly generated by the temporal increase of oxygen in this depth range in the period of 1975-1984 (Fig. 12e). We had not yet specified the cause of this temporal increase of oxygen. It is known that coastal region of southern Japan Sea sometimes experiences coastal upwelling (Nakada and Hirose 2009), and such process may be a part of the cause of this event.

In winter, significant winter mixed layer down to $150 \mathrm{~m}$ was developed (Fig. 3g). Similar to YB, winter mixed layer waters were saturated with oxygen, but absolute concentration of oxygen showed negative trend following to the long-term decrease of $\mathrm{DO}_{\text {sol }}$ due to the warming (Table 3, Fig. 12f-i 
Table 3 The same as in Table 2 but for winter data. AW is omitted from this table, as analysis of winter data was not carried out for this area

\begin{tabular}{|c|c|c|c|}
\hline Depth Range & ETS & WB & YB \\
\hline \multicolumn{4}{|l|}{$[0-1 \mathrm{~m}]$} \\
\hline Temp & $0.01 \pm 0.01$ & $0.05 \pm 0.01$ & $0.08 \pm 0.02$ \\
\hline Sal & $-0.001 \pm 0.001$ & $-0.002 \pm 0.005$ & $-0.002 \pm 0.001$ \\
\hline DO & $0.11 \pm 0.28$ & $-0.16 \pm 0.08^{\#}$ & $-0.50 \pm 0.12^{\#}$ \\
\hline $\begin{array}{l}\mathrm{DO}_{\text {sol }} \\
{[50 \pm 3 \mathrm{~m}]}\end{array}$ & $-0.06 \pm 0.06$ & $-0.27 \pm 0.06$ & $-0.54 \pm 0.14$ \\
\hline Temp & $0.01 \pm 0.01$ & $0.05 \pm 0.01$ & $0.06 \pm 0.02$ \\
\hline Sal & $0.000 \pm 0.001$ & $-0.006 \pm 0.002$ & $0.000 \pm 0.001$ \\
\hline DO & $-0.06 \pm 0.10$ & $-0.28 \pm 0.08^{\#}$ & $-0.29 \pm 0.16$ \\
\hline $\begin{array}{l}\mathrm{DO}_{\text {sol }} \\
{[100 \pm 5 \mathrm{~m}]}\end{array}$ & $-0.07 \pm 0.14$ & $-0.29 \pm 0.06$ & $-0.42 \pm 0.17$ \\
\hline Temp & $0.02 \pm 0.02$ & $0.05 \pm 0.01$ & $0.02 \pm 0.03$ \\
\hline Sal & $-0.001 \pm 0.002$ & $-0.003 \pm 0.002$ & $-0.001 \pm 0.001$ \\
\hline DO & $-0.12 \pm 0.19$ & $-0.23 \pm 0.07^{\#}$ & $-0.50 \pm 0.21$ \\
\hline $\begin{array}{l}\mathrm{DO}_{\text {sol }} \\
{[150 \pm 5 \mathrm{~m}]}\end{array}$ & $-0.10 \pm 0.17$ & $-0.31 \pm 0.07$ & $-0.16 \pm 0.21$ \\
\hline Temp & & $0.03 \pm 0.03$ & $0.00 \pm 0.03$ \\
\hline Sal & & $0.000 \pm 0.001$ & $-0.001 \pm 0.001$ \\
\hline DO & & $-0.26 \pm 0.10^{\#}$ & $-0.42 \pm 0.21^{\#}$ \\
\hline $\begin{array}{l}\mathrm{DO}_{\text {sol }} \\
{[200 \pm 5 \mathrm{~m}]}\end{array}$ & & $-0.17 \pm 0.19$ & $0.04 \pm 0.21$ \\
\hline Temp & & $0.00 \pm 0.04$ & $-0.01 \pm 0.02$ \\
\hline Sal & & $0.000 \pm 0.001$ & $-0.0003 \pm 0.0005$ \\
\hline DO & & $-0.24 \pm 0.16$ & $-0.33 \pm 0.24^{\#}$ \\
\hline $\begin{array}{l}\mathrm{DO}_{\text {sol }} \\
{[300 \pm 5 \mathrm{~m}]}\end{array}$ & & $0.02 \pm 0.28$ & $0.09 \pm 0.18$ \\
\hline Temp & & & $0.000 \pm 0.004$ \\
\hline Sal & & & $0.0004 \pm 0.0002$ \\
\hline DO & & & $-0.51 \pm 0.23^{\#}$ \\
\hline $\mathrm{DO}_{\text {sol }}$ & & & $0.00 \pm 0.04$ \\
\hline
\end{tabular}

Appendix 2). In $200 \mathrm{~m}$, negative oxygen trend lost its statistical significance despite of satisfactory data numbers, mainly due to the temporal increase of oxygen from 1970 to 1980s (Fig. 12j in Appendix 2). The cause of this temporal increase of oxygen was discussed in Appendix 3.

\subsection{East of the Tsushima straight}

Similar to the upper layers of other three regions, this region was filled with saline Tsushima Warm Current (TWC) overlaid with fresh, warm East China Sea (ECS) surface water in summer season (Fig. $3 \mathrm{j}$ and k, Onitsuka et al. 2007). Both water temperature and salinity showed no trend in all depth ranges, except the $100 \pm 5 \mathrm{~m}$ where salinity showed little freshening trend (Table 2). As this result, $\mathrm{DO}_{\text {sol }}$ showed no trend in summer ETS. Nevertheless, oxygen concentration showed significant decrease after 1985 in all isobaths (Fig. 31). This was the distinct feature of ETS, as oxygen had either stayed constant or increased on the isobaths shallower than $100 \mathrm{~m}$ in all other regions (Tables 2), and these trends were led by the longterm change of $\mathrm{DO}_{\mathrm{sol}}$. We will discuss about the possible source of oxygen variation in summer ETS in Sect. 4.2.

Water temperature in winter ETS showed large interdecadal variation, while the variation was not monotonic and hence no trend was observed in all depth ranges (Fig. 3j, Table 3). Salinity was almost stable (Table 3 ). Oxygen also showed large inter-decadal variation, and hence its trend component was statistically insignificant (Table 3, Fig. 13d-f in Appendix 2).

\section{Discussion}

\subsection{Two origins of oxygen variation in $\mathrm{YB}, \mathrm{AW}$, and WB: Solubility and JSPW}

Based on the analyses in each region, long-term variation of oxygen in $\mathrm{YB}, \mathrm{AW}$, and $\mathrm{WB}$ can be summarized as two major types of trend:

(1) Trend observed mainly in upper waters, in which the observed variation of oxygen concentration was consistent with that of $\mathrm{DO}_{\text {sol }}$. This type of variation includes both positive and negative trend, reflecting negative and positive trend of water temperature, respectively.

(2) Trend observed mainly in deep water, in which oxygen concentration was decreased independent to the variation of $\mathrm{DO}_{\text {sol }}$.

The vertical distributions of these two trend types in each region and season are summarized in Fig. 4.

The upper boundary of the Trend Type 2 in summer season existed at $150 \mathrm{~m}$ in $\mathrm{YB}$ and $\mathrm{WB}$, while it was located at $300 \mathrm{~m}$ in $\mathrm{AW}$. Although negative oxygen trends were also observed in 150-200 m of summer AW, its statistical significance was not enough due to the small data numbers in these depth ranges (Table 2). In winter, the upper boundary of Trend Type 2 was slightly shoaled to $100 \mathrm{~m}$ in YB, while it was stayed at $150 \mathrm{~m}$ in AW. The upper 
(a)

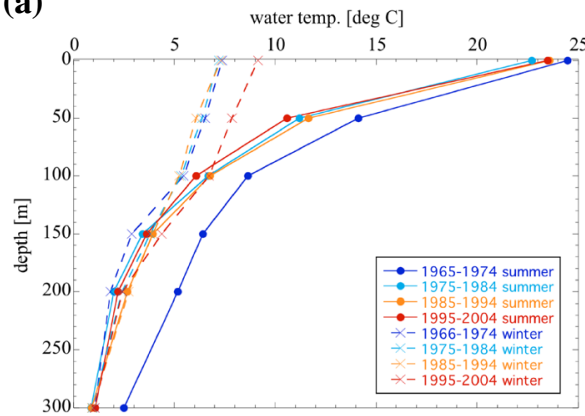

(d)

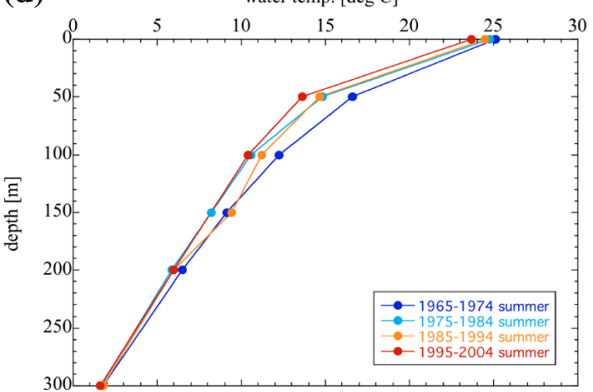

(g)

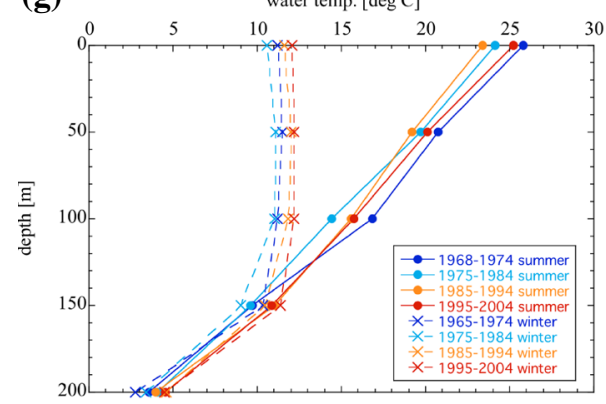

(j)

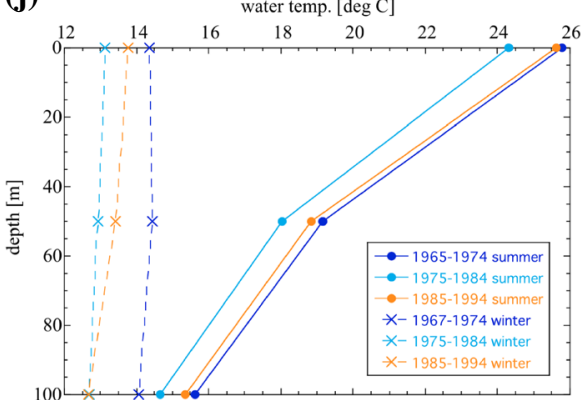

(b)

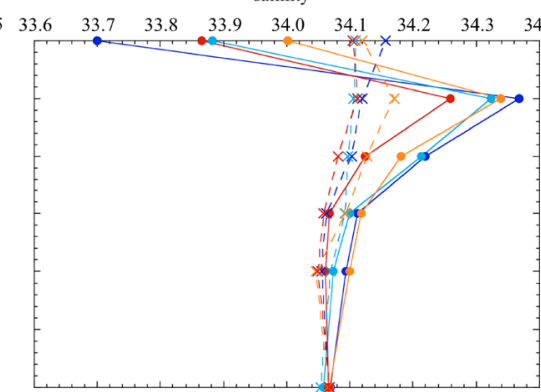

(e)

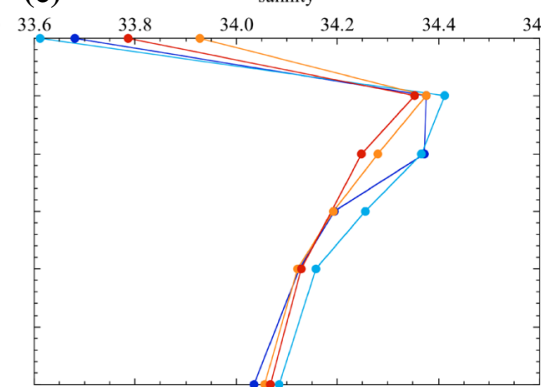

(h)

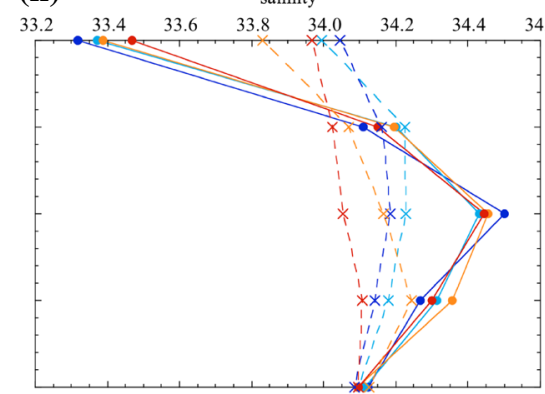

(k)

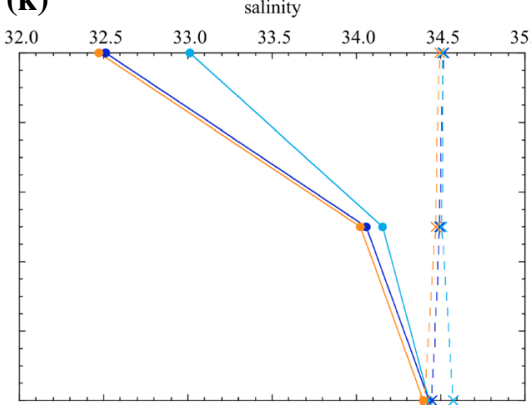

(c)

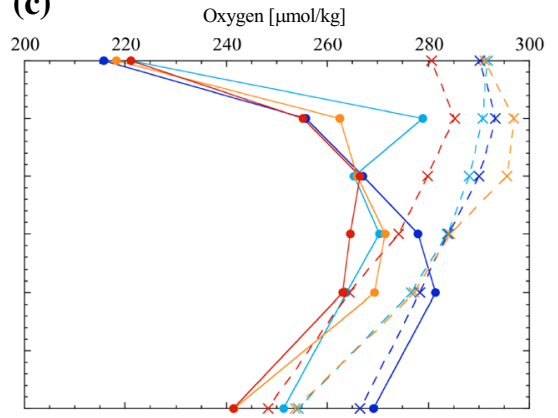

(f)

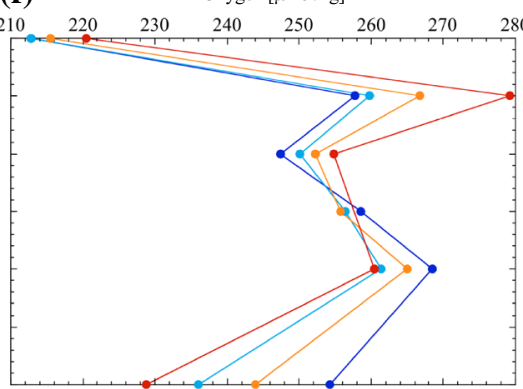

(i) Oxygen $[\mu \mathrm{mol} / \mathrm{kg}]$

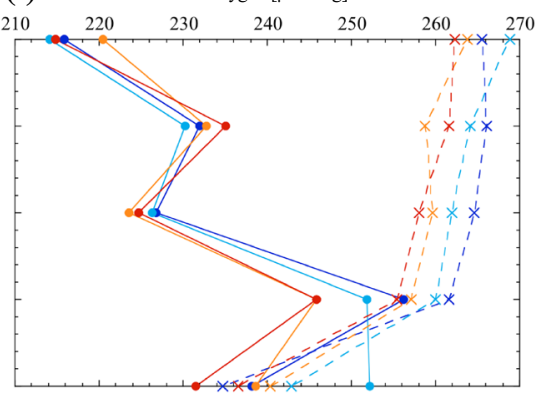

(l) $\quad$ Oxygen $[\mu \mathrm{mol} / \mathrm{kg}]$
Fig. 3 Vertical profiles of a water temperature, $\mathbf{b}$ salinity, and $\mathbf{c}$ dissolved oxygen in YB averaged for the period of 1965-1974 (blue), 1975-1984 (sky blue), 1985-1994 (orange), and 1995-2004 (red). Solid circles with solid lines denote summer profiles, while the Xs with dashed lines denote winter profiles. Error bars of each plot was omitted to keep visibility. d-f Same as a-c but for AW. Winter profiles were not shown in these figures because of no data. $\mathbf{g}$ ) -i Same as $(\mathbf{a}-\mathbf{c})$ but for WB. $\mathbf{j}-\mathbf{l}$ Same as $(\mathbf{a}-\mathbf{c})$ but for ETS boundary of JSPW is typically set at $300 \mathrm{~m}$ (e.g., Senju et al. 1999), and we directly observed the oxygen trend of this depth in YB and AW. Further oxygen data were able to be obtained from the deeper layers $(400 \pm 10 \mathrm{~m}$ and
$500 \pm 10 \mathrm{~m}$ ) in $\mathrm{YB}$ and $\mathrm{AW}$, although number of data on an isobaths became smaller and existence of data-absent period became larger with depth became deeper. Oxygen trends additionally calculated in these isobaths are listed 
in Table 4. A relatively low decreasing trend of oxygen was observed in the $500 \pm 10 \mathrm{~m}$ isobaths of summer AW $\left(0.33 \pm 0.12 \mu \mathrm{mol} \mathrm{kg}{ }^{-1} \cdot \mathrm{y}^{-1}\right.$, Table 4$)$. As most of the data on these isobaths in this region were obtained from the slope area of the Sado Ridge (Appendix 1), local vertical water movement along the ridge slope may have made some affection to produce such relatively low trend. Except these isobaths in summer AW, the rates of oxygen decrease observed in the isobaths deeper than $300 \mathrm{~m}$ was settled in the range from $0.51 \pm 0.23 \mu \mathrm{mol} \mathrm{kg}-1 \cdot \mathrm{y}^{-1}(300 \pm 5 \mathrm{~m}$, winter YB) to $0.80 \pm 0.30 \mu \mathrm{mol} \mathrm{kg}{ }^{-1} \cdot \mathrm{y}^{-1}(300 \pm 5 \mathrm{~m}$, summer AW). Reported rates of oxygen decrease in JSPW in the historical reports varied from $0.46 \pm 0.004 \mu \mathrm{mol} \mathrm{kg} \mathrm{kg}^{-1} \cdot \mathrm{y}^{-1}$ (Watanabe et al. 2003) to $0.69 \mu \mathrm{mol} \mathrm{kg}{ }^{-1} \cdot \mathrm{y}^{-1}$ (average of Eastern Japan Basin and Yamato Basin, Gamo et al. 2014), and the trend observed at the isobaths deeper than $300 \mathrm{~m}$ depth in the present study was identical to, or even larger than, that observed in JSPW. Therefore, we can consider that this is the same signal of oxygen decrease that has been detected in JSPW in the previous studies. Above this depth range, the rate of oxygen decrease became smaller with decreasing depth; however, a statistically significant negative trend of oxygen was still detectable and was larger than the estimated decreasing rate of $\mathrm{DO}_{\text {sol }}$ up to $150 \mathrm{~m}$ for WB (both summer and winter), $150 \mathrm{~m}$ and $100 \mathrm{~m}$ in summer and winter, respectively, for YB. These results are the first evidence that waters along banks and continental shelves of the southern Japan Sea have already faced deoxygenation.

Oxygen in subsurface waters could have been decreased, if vertical flux of organic material transported from the productive mixed layer has been increased. However, there are no coincided understanding about the long-term trend of primary production in southern Japan Sea. Although chlorophyll concentration showed increasing trend, numerical model simulation of primary production exhibited longterm decrease (Ishizaka and Yamada 2019). As a situational evidence, Kodama et al (2016) pointed out that lateral transport of nitrate from the ECS to Japan Sea showed long-term increase at the rate of $0.005 \mathrm{Tmol} \cdot \mathrm{y}^{-1}$, and the observed long-term decrease of phosphate concentration in the upper layer of southern Japan Sea can be explained if this increased nitrate supply had caused increase of net primary production (i.e., net phosphate consumption). If their hypothesis is true, $0.005 \mathrm{Tmol} \cdot \mathrm{y}^{-1}$ increase of nitrate supply corresponds to the $64 \mu \mathrm{molC} \cdot \mathrm{m}^{-2} \cdot \mathrm{y}^{-1}$ increase of sinking organic carbon flux, assuming that all the supplied nitrate is consumed in the mixed layer in the southern half area of Japan Sea (ca. 515,000 $\mathrm{km}^{2}$ ). Even if we assume that all of this increased carbon flux is decomposed within the depth range of 150-300 $\mathrm{m}$ in water column, this process decreases oxygen only at the rate of $0.0005 \mu \mathrm{mol}$ $\mathrm{kg}^{-1} \cdot \mathrm{y}^{-1}$. Since the observed decreasing rates of oxygen at these depth ranges were far larger than this simulation, we must seek other mechanism than the change of biological process to explain the observed long-term trend of oxygen.

The depth ranges of 100-300 m corresponded to JIW, that has its origin in the winter surface water of the western edge of the subarctic front (Senjyu 1999). The observed negative trend of oxygen in these depth ranges thus can be explained either by vertical propagation of deoxygenation signal of JSPW, or decrease of JIW formation rate. The later process also diminishes fresh water transport, and hence salinity in these depth ranges should have been increased if the later process had occurred. However, increasing trend of salinity was not observed in the 100-300 m depth range of $\mathrm{YB}, \mathrm{AW}$, and $\mathrm{WB}$, with single exception of the $150 \mathrm{~m}$ isobaths in summer AW $\left(0.008 \pm 0.002 \mathrm{y}^{-1}\right.$, Table 2). This result indicates that the formation rate of JIW has not been changed significantly throughout this period, and hence, a decreased rate of JIW formation was likely not the cause of the observed oxygen decrease. Water temperature in the 100-300 m depth range showed cooling trends in summer season, with the exception of $150 \mathrm{~m}$ isobaths in summer AW $\left(0.10 \pm 0.07^{\circ} \mathrm{C} \cdot \mathrm{y}^{-1}\right.$, Table 2$)$. This also implies that the extent of winter cooling at the formation area of JIW was not diminished during this period, and hence the formation rate of JIW should have not been decreased.

Senjyu (1999) pointed out that newly formed JIW undergoes strong diapycnal mixing with JSPW during its eastward propagation. This means that JIW in its downstream areas, such as $\mathrm{WB}, \mathrm{AW}$, and $\mathrm{YB}$, contains a certain portion of JSPW water, and hence the deoxygenation signal of JSPW can easily propagate to JIW. Based on this consideration, it was implied that the observed negative trend of oxygen in depth ranges of $100-300 \mathrm{~m}$ is due to the upward propagation of JSPW deoxygenation.

The lower boundary of Trend Type 1 lies $100 \mathrm{~m}$ in AW (Fig. 4a). We could observe a signal of oxygen increase also in the surface waters of YB and WB in summer (Table 2), although these signals didn't have statistical significance in the linear trend analysis due to large shortterm variation. Water temperature on the isobaths above $100 \mathrm{~m}$ showed cooling trend in summer season, with the only exception of the surface water of summer WB (no trend, Table 2). Recent report of Japan Meteorological Agency shows that surface water of southwestern Japan sea shows warming trend in summer, in far longer time scale than the present study (ca, 1900s to 2010s; http://www. data.jma.go.jp/gmd/kaiyou/data/shindan/a_1/japan_warm/ cfig/warm_area.html?area=E). Their result, however, also shows temporal cooling of summer surface waters during the period from 1960 to 1990s. As measurement of oxygen in Japan Sea had started mainly from 1960s, the result of the present study was based on the data from 1960s to early half of 2000s. This overlap explains why the present result 
show cooling of summer surface water, despite of warming trend in centennial time scale. Kodama et al. (2016) found similar trend of surface cooling in the almost the same area with WB. Such cooling trends have led positive trends of $\mathrm{DO}_{\text {sol }}$ in the summer surface waters above $100 \mathrm{~m}$ (Table 2), making primary forcing of oxygen increase in summer Type 1 waters.

Interestingly, the lower boundary of Trend Type 1 significantly deepened in winter and directly bordered Trend Type 2 (Fig. 4b; Table 3). This is natural when considering that both Trend Types 1 and 2 have negative trends of oxygen, and the singular difference between them is whether the rate of the trend is the same as, or larger than, that of $\mathrm{DO}_{\text {sol. }}$. In summer, Trend Type 1 shows a positive oxygen trend, and as this result, the depth ranges with no oxygen trend emerges in between Trend Types 1 and 2. In this case, absence of oxygen trend in these depth ranges can be interpreted as the signal of the positive trend from the surface being offset by the signal of the negative trend of JSPW. From this viewpoint, we can consider that the water in these depth ranges is also affected by the deoxygenation signal of JSPW, and the upper boundary of the propagation of the deoxygenation signal from JSPW is the lower boundary of the Trend Type 1, rather than being the upper boundary of the Trend Type 2 .

\subsection{Possible cause of oxygen variation in ETS}

The deepest bottom depth of ETS is $120 \mathrm{~m}$; hence, the signal of oxygen decrease that was observed in summer ETS must be transported horizontally to this area, rather than be propagated from deep waters. The TWC, the main current system of ETS, flows into this area from the ECS. Therefore, we can consider ECS as one possible source of deoxygenation signals. Previous studies have shown that severe oxygen decrease is ongoing in several areas of the ECS, such as the Changjiang Estuary (e.g., Qian et al. 2017; Wang et al. 2016) and Yellow Sea (Wei et al. 2019). The negative oxygen trend developed in these areas may be horizontally propagated, although their signal must cross over the ECS to reach the ETS.

Another possible source is the Korea Straight Cold Bottom Water (KSCBW), which flows into the west channel of the Tsushima Straight and interacts with subsurface waters of the east channel below $50 \mathrm{~m}$ depth (e.g., Cho and Kim, 1998; Isobe 1995; Kim et al. 2006). Since KSCBW has its origin in the upper portion of JSPW (Cho and Kim 1998), it may be possible that KSCBW transports the deoxygenation signal of JSPW into the subsurface layer of ETS. Because KSCBW develops in the summer season and almost entirely disappears in winter (Cho and Kim 1998; Isobe 1995; Kim et al. 2006), it could be stated that this feature corresponds to the present results, in that significant negative oxygen trend appears in ETS only in the summer season.

To assess which source (either ECS or KSCBW) actually affect to ETS, an additional time series analysis was carried out for the area named West of the Tsushima Straight (WTS; $128^{\circ} \mathrm{E}-129.5^{\circ} \mathrm{E}$ and $33^{\circ} \mathrm{N}-34^{\circ} \mathrm{N}$ in the ECS, for the period 1967-2006, with $\mathrm{N}=218$ and 298 for summer and winter, respectively, Brown dashed line box in Fig. 1). As KSCBW does not extend to the area west of Tsushima Island (Cho and Kim, 1998; Teagure et al. 2002), it was expected that we would not be able to detect the Trend Type 2 in WTS if KSCBW is the main source of oxygen decrease in this area.

The results of the WTS analysis are listed in Table 5. Negative oxygen trend was detected in WTS, both in summer and winter. Moreover, the maximum rate of the decreasing trend of oxygen in summer WTS $\left(-0.77 \pm 0.11 \mu \mathrm{mol} \mathrm{kg} \mathrm{kg}^{-1} \cdot \mathrm{y}^{-1}\right.$ in $50 \pm 3 \mathrm{~m}$, Table 5) was almost the same as that observed in summer ETS $\left(-0.70 \pm 0.10 \mu \mathrm{mol} \mathrm{kg}{ }^{-1} \cdot \mathrm{y}^{-1}\right.$ in $50 \pm 3 \mathrm{~m}$, Table 2). These results indicate that the deoxygenation observed in ETS was actually the signal transported from WTS, and hence, from further upstream areas of ECS.

For WTS, a signal of oxygen decreases larger than that of $\mathrm{DO}_{\text {sol }}$ was observed in $50 \pm 3 \mathrm{~m}$ and $100 \pm 5 \mathrm{~m}$ depth ranges in winter, a feature which was not observed for ETS in winter. The volume transport of the TWC shows distinct seasonal variation, with that in winter falling two-thirds of that in summer (e.g., Takikawa et al. 1995). This feature indicates that the deoxygenation signal in the subsurface water of the WTS may be able to propagate to ETS only weakly in winter. Strong vertical mixing within ETS in winter (Fig. 3j) may erase the deoxygenation signal propagated from the west by resetting oxygen concentration to $100 \%$ equilibrium with the atmosphere, although WTS, where bottom depth is roughly the same with that of ETS, kept significant negative trend even in the winter season. No trend of $\mathrm{DO}_{\text {sol }}$ in winter ETS was sustained by no trend of water temperature, but so far we have no simple explanation why warming had not occurred in this area despite that significant warming was observed both in winter WTS and winter WB. Further study will be required to obtain concrete mechanism of winter reset of deoxygenation trend in winter ETS.

Because TWC further flows eastward and reached to WB and AW as FBTWC, signal of oxygen decrease in WTS might also reach to these regions. Watanabe et al. (2009) estimated mean current velocity of summer FBTWC in the area from ETC to WB as approximately $15 \mathrm{~cm} / \mathrm{s}$. As WB is apart from ETC by approximately $500 \mathrm{~km}$, we can expect that waters that flow out from ETC will reach WB by approximately 39 days. Thus, we can expect that deoxygenation signal of summer ETC should be observed 
also in summer WB if this signal is not disturbed by water mixing etc. However, summer water of WB did not show any temporal oxygen decrease in the depth range above $100 \mathrm{~m}$ (Table 2). Watanabe et al. (2009) also reported that eddy kinetic energy of summer FBTWC becomes significantly high in the area east of Oki island, i.e., the area just between ETC and WB. This result indicates that the signal of oxygen decrease observed in summer WTC had disappeared by the water mixing on the way to its eastward propagation to WB.

\subsection{Possible impact of observed deoxygenation on biology}

Typical threshold of oxygen under which most of saltwater fishes die is $62 \mu \mathrm{mol} \mathrm{kg}{ }^{-1}(2.05 \mathrm{mg} / \mathrm{L}$, Vaquer-Sunyer and Duarte 2008), and observed oxygen concentration in the waters above $300 \mathrm{~m}$ depth was fairly larger than this threshold in 1960. However, nonlethal impact of oxygen decline, such as reduction of growth and/or failure of reproduction often manifests at far larger oxygen concentration than this "lethal threshold." For example, Atlantic cod starts to decrease their growth rate at the threshold of $200 \mu \mathrm{mol} \mathrm{kg}^{-1}$ oxygen (Chabot and Claireaux 2008). These impacts are similarly grave for the fishes because the species receiving these "sublethal" impacts could suffer a disadvantage in natural among-species competition. Numbers of experiments had estimated oxygen threshold of these sublethal impacts (namely sublethal threshold) for individual fish species, but accumulated knowledge so far is not enough to figure out general sublethal threshold of oxygen for each oceanic area. Vaquer-Sunyer and Duarte (2008) summarized historically estimated sublethal hypoxia threshold for many species and figured out those mean value for each taxa. For fish, estimated mean sublethal threshold was $4.41 \mathrm{mg} / \mathrm{L}$ (ca. $134 \mu \mathrm{mol} \mathrm{kg}^{-1}$ ). In this study, this global average value of sublethal threshold is tentatively adopted to assess biological impact of oxygen decrease in the upper waters of southern Japan Sea.

Although the oxygen concentration of JSPW showed a high rate of long-term decrease, previous studies repeatedly mentioned that the absolute value of oxygen concentration in JSPW is very high compared to deep waters in other ocean basins (e.g., Gamo et al. 2014). This situation is also true for subsurface waters of the Japan Sea above $300 \mathrm{~m}$ depth. Average \pm 2 SD concentration of oxygen in each area and each depth range for 1960 are listed in Tables 6 and 7. In 1960, oxygen concentrations were larger than the threshold of $134 \mu \mathrm{mol} \mathrm{kg} \mathrm{kg}^{-1}$ by at least $100 \mu \mathrm{mol} \mathrm{kg} \mathrm{kg}^{-1}$ for BW, AW, and YB and by $55 \mu \mathrm{mol} \mathrm{kg}{ }^{-1}$ for WTS and ETS. These results imply that the observed oxygen decrease may have had no immediate impact on ocean biology. However, threshold values show large variability depending on species, especially in those that have adapted to high oxygen concentrations tend to have high sublethal thresholds of oxygen. For example, Atlantic salmon have been found to reduce their growth rate when the ambient oxygen concentration drops below $174 \mu \mathrm{mol} \mathrm{kg}{ }^{-1}$ (ca. $70 \%$ saturation in $16{ }^{\circ} \mathrm{C}$ seawater, Remen et al. 2012), and Atlantic cod have been shown to have an even larger sublethal threshold of oxygen, decreasing their growth rate at the threshold of $200 \mu \mathrm{mol} \mathrm{kg}{ }^{-1}$ (70\% saturation in $10^{\circ} \mathrm{C}$ seawater, Chabot and Claireaux 2008). Low tolerance of the above two species toward oxygen are particularly important for Japan, as fisheries in the Japan Sea make use of related species (e.g., chum salmon and pacific cod) as one of main fish resources.

In principle, each species has adapted to the environment of their original habitat; therefore, any species should be expected to experience stress when one environmental factor deviates from its original range of variation. From this point of view, the concept of time of emergence (ToE: e.g., Giorgi and Bi, 2009; Keller et al. 2014) provides a useful index, as it indicates the point at which the environment of a habitat exceeds its natural variability after the ToE period. Wang et al. (2020) introduced a new concept related to ToE, year of emergence (YoE), which denotes the year in which an environmental parameter deviates from its natural variation from that of the preindustrial era. Unfortunately, for the present study, we could not specify the oxygen concentration for each area and depth range at the time of the preindustrial period. Therefore, instead we introduced a modified index of $\mathrm{YoE}_{1960}$, which refers to the year in which the average concentration of oxygen becomes smaller than the average minus 2SD in 1960 (Fig. 5). The present study also calculated the year in which the estimated concentration of oxygen reaches the predefined sublethal threshold of oxygen $\left(134 \mu \mathrm{mol} \mathrm{kg}^{-1}\right)$, referred to hereafter as year of threshold (YoT). As the calculation of $\mathrm{YoE}_{1960}$ and YoT implicitly assume that the observed oxygen trend can be extrapolated towards future, it is critical to confirm that the calculated trend of oxygen in Tables 2, 3 , and 5 are not influenced by the existence of decadal variation, and hence these figures are the actual reflectance of long-term trend. To assess this, we calculated two additional oxygen trends in that the observation period were changed from the original one (Appendix 3). $\mathrm{YoE}_{1960}$ and YoT were then calculated only for the areas and reference depth ranges, in that the calculated trend in Tables 2, 3, and 5 were robust against the change of the observation period (i.e., trends with superscript of \# in Tables 2, 3, and 5, see also Tables 8 and 9 in Appendix 3). The results were listed in Tables 6 and 7 .

For summer, $\mathrm{YoE}_{1960}$ was prior to 2020 , or soon after 2020 , in the depth ranges of $50-100 \mathrm{~m}$ for WTS, $50 \mathrm{~m}$ for ETS, $150-200 \mathrm{~m}$ for WB, $300 \mathrm{~m}$ for AW, and $150-300 \mathrm{~m}$ 
for YB; thus, all areas in the Japan Sea analyzed in the present study feature a depth range in which organisms are facing low oxygen concentrations that were not experienced before 1960 . These waters are already potentially hazardous for the most vulnerable species in the ecosystem, and hence a detailed assessment is required to further understand the situation. Table 6 also shows that oxygen concentration is expected to drop below the general sublethal threshold of $134 \mu \mathrm{mol} \mathrm{kg} \mathrm{kg}^{-1}$ by the end of this century for the depth ranges of 50-100 $\mathrm{m}$ for WTS, and $50 \mathrm{~m}$ for ETS. By the end of twenty-second century, $100 \pm 5 \mathrm{~m}$ for ETS, $200 \pm 5 \mathrm{~m}$ for $\mathrm{WB}$, and $300 \pm 5 \mathrm{~m}$ for $\mathrm{AW}$ and YB are

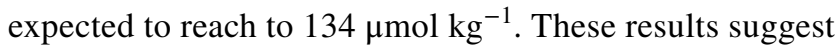
that despite of high oxygen concentrations in the present Japan Sea, the ongoing deoxygenation will exert a hazardous impact on the ecosystem of coastal shallow waters in the near future.

The oxygen environment was slightly improved in winter; however, values of $\mathrm{YoE}_{1960}$ prior to 2020 were observed for WB (50-150 m) and YB (surface), and those of nearby 2020 were observed for WTS $(50 \mathrm{~m}$ and $100 \mathrm{~m}$ ) and YB $(150 \mathrm{~m}$ and $300 \mathrm{~m})$. Notably, the observed oxygen trend at the depth ranges of 50-100 $\mathrm{m}$ in winter WB and surface of winter YB were the Trend Type 1 (Fig. 4); hence, saturation level of oxygen in these water masses have not been changed throughout the study period. Helm (2011) argued that approximately $15 \%$ of the observed decrease in global ocean oxygen content can be explained by the change in $\mathrm{DO}_{\text {sol }}$ caused by the global warming. Agreeably, the present results further indicate that a change in $\mathrm{DO}_{\text {sol }}$ could lead to the potential risk of ecological suboxic impact, without the support of enhanced stratification.

\section{Conclusion}

This study analyzed temporal variations in oxygen concentration in waters shallower than $300 \mathrm{~m}$ in the southern coastal areas of the Japan Sea. The results revealed that the oxygen concentrations in these waters have decreased, similar to those observed in JSPW. The mechanism of oxygen decreases differed between the Tsushima Strait area and other coastal areas. In the coastal area of the southern Japan Sea, the oxygen decrease in the lower subsurface water was caused by the upward propagation of the deoxygenation signal from JSPW (i.e., Trend Type 2). In waters with shallower depth ranges, oxygen decrease was caused in winter season by reduced solubility, which itself was caused by the warming (i.e., Trend Type 1). The upper boundary of the Trend Type 2 was located around $150-300 \mathrm{~m}$ in the summer season, while it shoaled to $100-150 \mathrm{~m}$ in winter. Trend Type 1 existed in surface layers with a thickness of less than $100 \mathrm{~m}$ in summer, whereas it occupied the entire depth range from the surface to the upper boundary of Trend Type 2 in winter. In Tsushima Strait area; however, horizontal propagation of the signal of oxygen decreases from the ECS caused significant negative oxygen trend throughout the entire water column in summer season.

As a result of the deoxygenation observed in the present study, oxygen concentration has already dropped below the original range of the natural variation of 1960 levels in several depth ranges of the southern Japan Sea coast. Moreover, it is predicted that part of the subsurface water in the Tsushima Strait area in summer will reach to the general sublethal threshold of oxygen $\left(134 \mu \mathrm{mol} \mathrm{kg}^{-1}\right)$ by the end of this century. By the end of twenty-second century, the bottom water of other southern Japan Sea coastal areas is also expected to reach this sublethal threshold.

Previous studies have focused mainly on deoxygenation in JSPW, revealing that the absolute concentration of oxygen in JSPW is significantly higher than those of the deep waters of other ocean basins. As a result, few arguments have been made regarding the risk of deoxygenation to the Japan Sea ecosystem. This study, however, shows that deoxygenation is presently ongoing in the shallow waters of the Japan Sea, at rates significantly high to cause potential risk to the ecosystem in the present and/or near future of this region. This study thus highlights the urgent need for ecological assessment of the ongoing deoxygenation in the Japan Sea, especially that in shallow waters.

\section{Appendix 1: selection of analytical area based on horizontal homogeneity}

We firstly set potential analytical area widely in each of four regions (YB, AW, WB and ETC), and then narrowed it based on the horizontal homogeneity of three water properties (water temperature, salinity and dissolved oxygen) in each reference depth ranges from 0 to $300 \mathrm{~m}$. Detailed oceanographic settings and the consequent area selection in each region was as follows:

Yamato bank (YB): This bank with the shallowest depth of $236 \mathrm{~m}$ locates center of Japan Sea, dividing Japan Basin and Yamato Basin. Subpolar front locates at around $39.5^{\circ} \mathrm{N}$ (Fig. 6a-e), and interannual movement of this front (e.g., Minobe et al. 2004) makes horizontal distribution of three water properties very heterogeneous north of this latitude. We, therefore, narrowed the study area to south of $39.25^{\circ}$ $\mathrm{N}$. The data east of $136^{\circ} \mathrm{E}$ were then omitted, because no shallow area exists in this area south of $39.25^{\circ} \mathrm{N}$ (Fig. 1). The data west of $134^{0} \mathrm{E}$ was also omitted, because southward propagation of subpolar water was observed on the $100 \mathrm{~m}$ isobaths in winter (Fig. 6a, d). 
Off-Awashima Area $(A W)$ : This region contains two shallow areas: continental shelf that occupies west of Honshu Island with horizontal width of 30 miles and the Sado Ridge that occupies north of the Sado Island with top depth of 150-500 m. The Mogami Trough divides these two shallow areas, with maximum depth of $3000 \mathrm{~m}$. Most of data observed in this region located on the Sado Ridge and its adjacent waters (Fig. 1). Some data located on the off-Honshu continental shelf, but part of the continental-shelf data east of $139.5^{\circ} \mathrm{E}$ were omitted because of the intrusion of extremely warm surface water $\left(>28^{\circ}\right.$ C, Fig. 10a). The First Branch of Tsushima Warm Current (FBTWC) flows northward through the area between the Sado and the Honshu Islands (e.g., Watanabe et al. 2006), and moderately warm, saline waters originated from this current filled entire study area west of $139.5^{\circ} \mathrm{E}$ (Fig. 7a, b).

Wakasa Bay (WB): Wakasa Bay is the largest bay in the southern coast of Japan Sea. Bottom depth gradually deepens towards north and reaches to $200 \mathrm{~m}$ and $300 \mathrm{~m}$ at around $35.8^{\circ} \mathrm{N}$ and $36^{\circ} \mathrm{N}$, respectively. FBTWC usually flows north of $36^{\circ} \mathrm{N}$ of this bay, and interannual variation of the flow pattern of this current causes wide variation of water temperature and salinity north of this latitude (e.g., Hase et al. 1999). We, therefore, omitted data north of $36.25^{\circ} \mathrm{N}$ (Fig. 8). South of this latitude, circulation flow formulates horizontally homogeneous water properties within the bay (Wada and Yamada, 1999), yet we omitted the data west of $135.25^{\circ} \mathrm{E}$ where intrusion of relatively cold water was observed in summer season (Fig. 8a). We also omitted data of coastal waters south of $35.6^{\circ} \mathrm{N}$ to avoid sporadic signal of river plume (Fig. 8b, d).

The east of the Tsushima Straight (ETS): This region consists of wide continental shelf between Japanese Archipelago and Korean Peninsula with bottom depth less than $200 \mathrm{~m}$. FBTWC filled entire this region (Kawabe 1982), and hence horizontal distribution of all three parameters were quite homogeneous within this region (Fig. 9). As this result, no stations were omitted based on the horizontal homogeneity assessment.

\section{Appendix 2: graphs of oxygen time series on all isobaths in each region and season}

Time series of oxygen in each depth range, season and area is shown in Figs. 4, 5, 6, 7, 8, 9, 10, 11, 12, 13, 14.
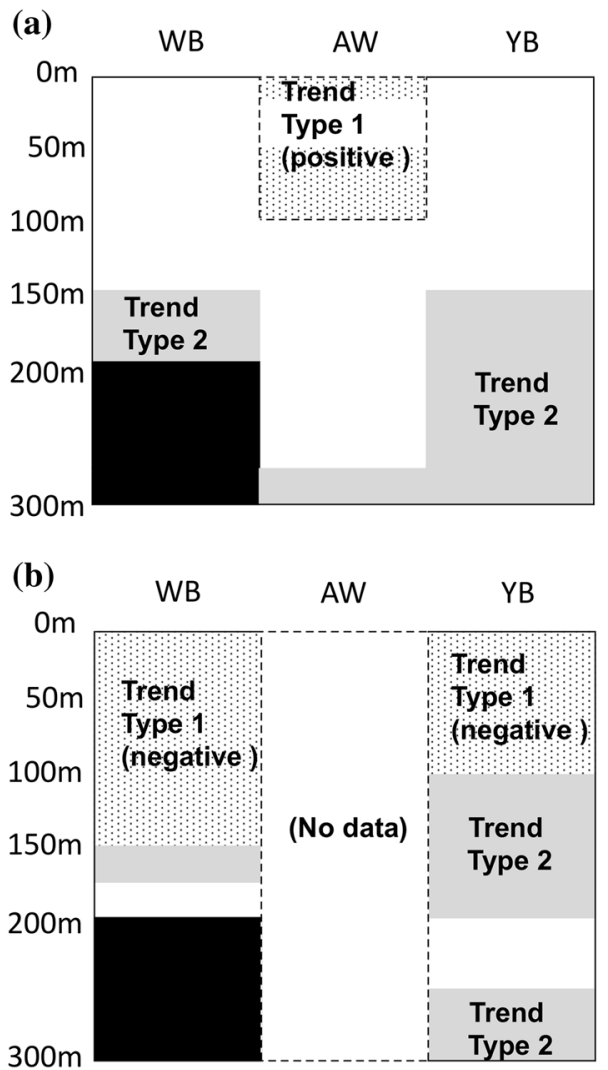

Fig. 4 Vertical distribution of the different types of oxygen trends in the southern Japan Sea coastal area in the a summer, and $\mathbf{b}$ winter seasons. Dotted and gray-colored areas indicate Trend Type 1 and 2, respectively. Black-colored area indicates the seafloor

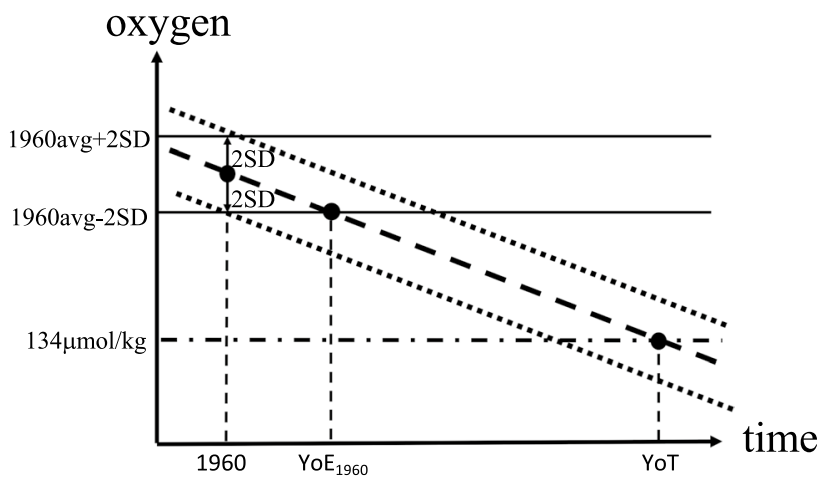

Fig. 5 Schematic diagram of $\mathrm{YoE}_{1960}$ and YoT. Dashed and dotted lines represent line of linear regression and its $\pm 2 \mathrm{SD}$ estimated from the observed oxygen data, respectively. $\mathrm{YoE}_{1960}$ is defined as the year when average oxygen concentration falls below the average-2SD value of 1960 . YoT is defined as the year when average oxygen concentration falls below $134 \mu \mathrm{mol} / \mathrm{kg}$ 
(a) Water temperature [deg C] at $50 \mathrm{~m}$

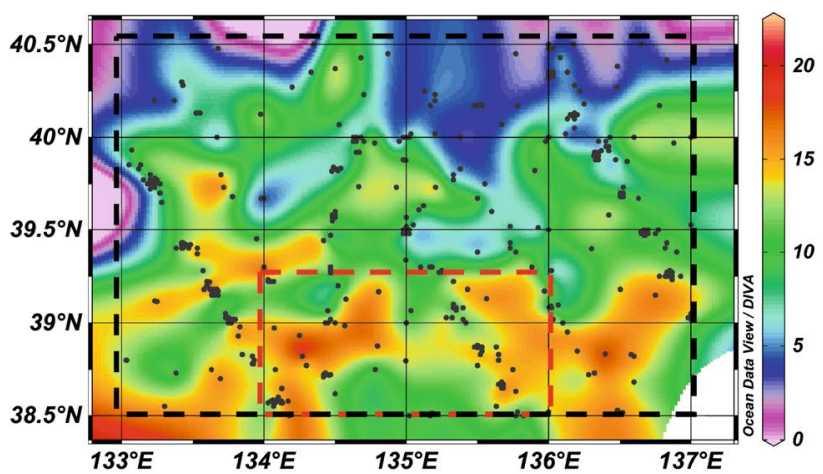

(b)

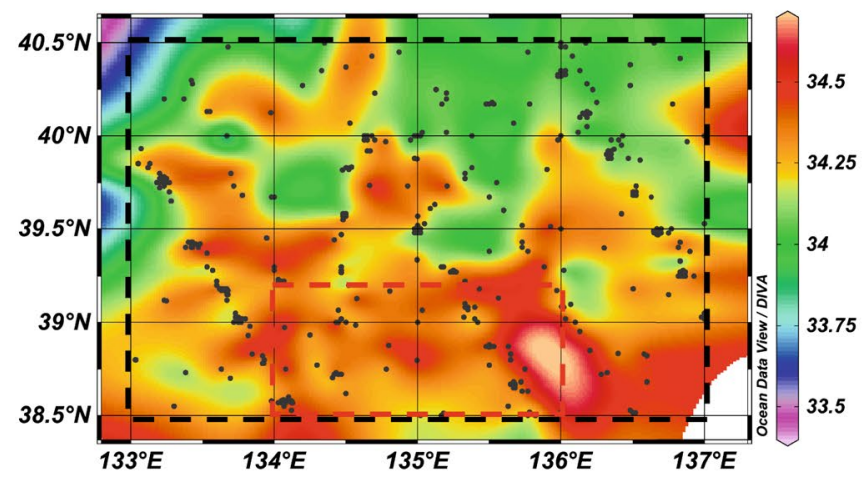

(c)

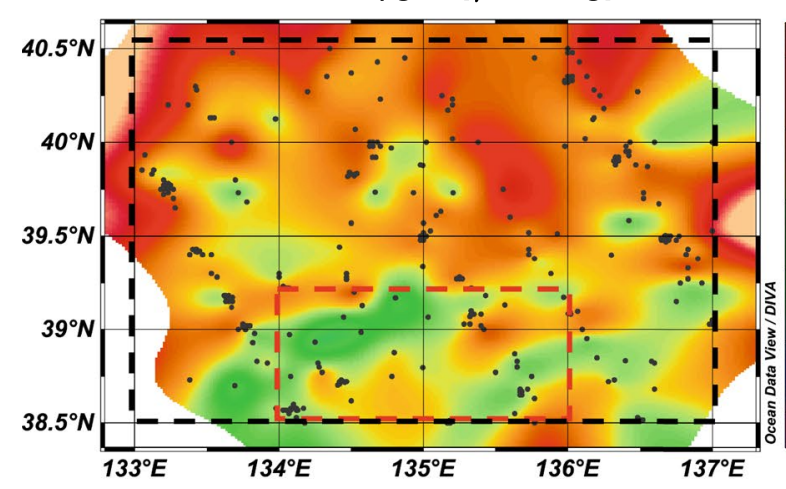

Fig. 6 Horizontal distribution of a water temperature, b salinity, and c dissolved oxygen on the $50 \mathrm{~m}$ isobaths in summer YB region. The black dashed line box indicates the area where the data were extracted from WOA18 at first, while the red dashed line box indicates the area selected for the following analysis after the horizontal homogeneity assessment. We made this kind of assessment for all the isobaths (d) Water temperature [deg C] at $100 \mathrm{~m}$

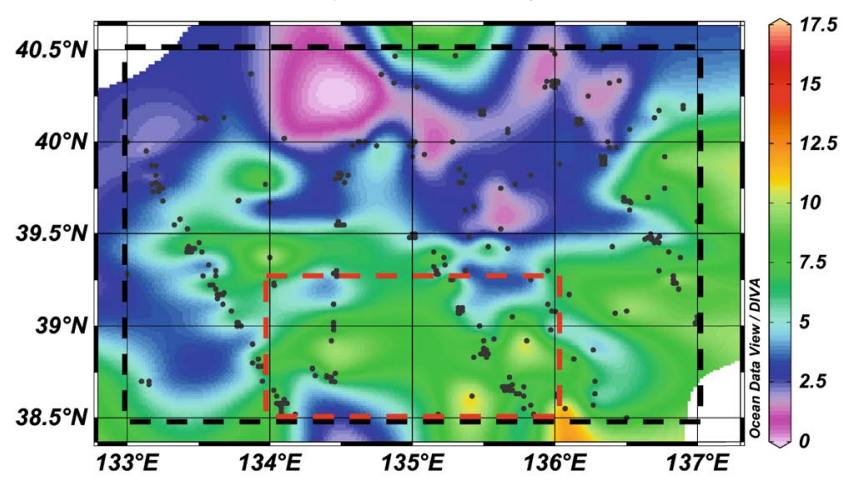

(e)

Salinity [psu] at $100 \mathrm{~m}$

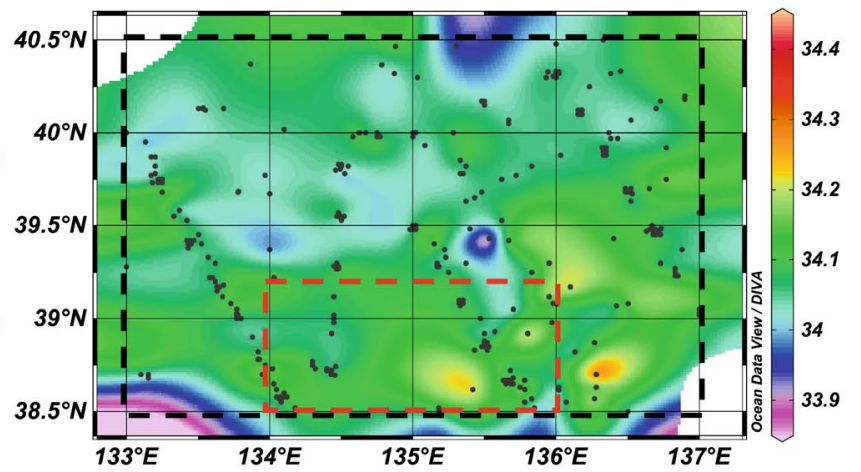

(f)

Oxygen [ $\mathrm{\mu mol} / \mathrm{kg}$ ] at $100 \mathrm{~m}$

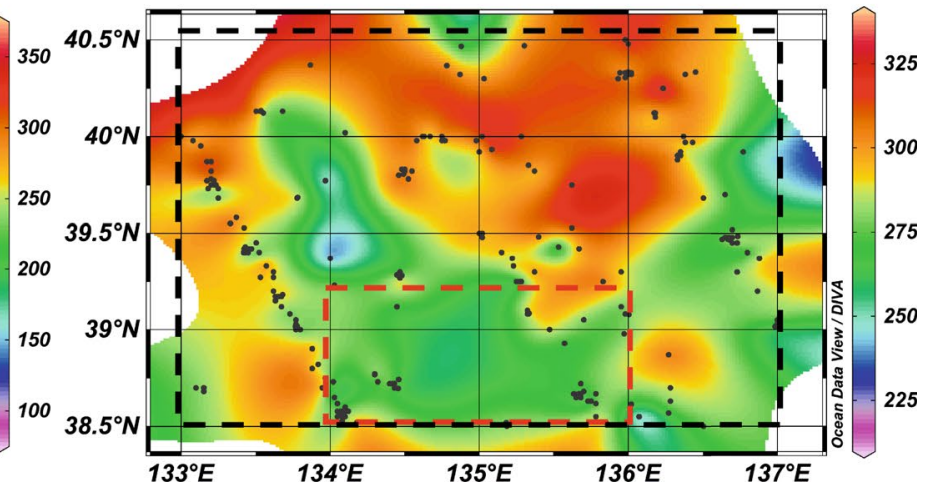

from 0 to $300 \mathrm{~m}$, but here we show the results of $50 \mathrm{~m}$ isobaths as an example, because horizontal variation of each property was the largest on these isobaths in summer YB. d-f The same as $(\mathbf{a}-\mathbf{c})$ but for the $100 \mathrm{~m}$ isobaths in winter YB. These isobaths were selected as an example because horizontal variation of each property was the largest on these isobaths in winter YB 
Fig. 7 Horizontal distribution of a water temperature, b salinity, and c dissolved oxygen on the $0 \mathrm{~m}$ isobaths in summer AW region. The meanings of black and red dashed line boxes were same as those of Fig. 6

\section{Appendix 3: Sensitivity assessment of oxygen trends to the observation period}

Watanabe et al. (2003) revealed the existence of bi-decadal oscillation superimposed to the long-term decreasing trend in the oxygen time series of JSPW. Time series of oxygen obtained in this study did not show clear signal of bi-decadal oscillation (Appendix 2). This result, however, does not directly mean absence of bi-decadal oscillation in the waters above JSPW, because large variation of oxygen in single time slices was enough to cover up small signal of decadal or bi-decadal scale variation. Surface waters could also contain many kinds of short-term variation of oxygen caused by local processes, and such signal can affect to the calculated rate of long-term trends in Tables 2, 3, and 5. Unfortunately, relatively large variation of oxygen prevented to obtain the signal of temporal variation with the time scale shorter than 20 years with statistical significance. In this study, therefore, dependency of the calculation results of oxygen trend on the observation period was assessed by comparing the following three estimations of oxygen trend for the same time series:

- Trend based on the original time series $\left(\mathrm{TR}_{\text {full }}\right)$.

- Trend by using the data that lacks the last ten years from the original time series.

$\left(\mathrm{TR}_{\text {-last } 10}\right)$.

- Trend by using the data that lacks the first ten years from the original time series.

$\left(\mathrm{TR}_{- \text {first10 }}\right)$.

$\mathrm{TR}_{\text {-last10 }}$ and $\mathrm{TR}_{\text {-first10 }}$ were calculated only for the isobaths on which $\mathrm{TR}_{\text {full }}$ was negative with the absolute value larger than its 1SD (Tables 2, 3, and 5). The results are listed in Tables 8 and 9 with TR $_{\text {full }}$. For most cases, both $\mathrm{TR}_{\text {-last10 }}$ and $\mathrm{TR}_{\text {-first10 }}$ showed statistically significant negative trend when $\mathrm{TR}_{\text {full }}$ was negative with statistical significance. In some case, whether $\mathrm{TR}_{\text {-last10 }}$ or $\mathrm{TR}_{\text {-first10 }}$ lost statistical significance due to the large variation of data, but sign of the trend had kept negative even in such cases. These features indicate that the negative trend of oxygen detected by $\mathrm{TR}_{\text {full }}$ is robust for the most areas and isobaths, although its rate can vary depending on the timing and length of observation.

An exception was observed in winter $\mathrm{YB}$, where $\mathrm{TR}_{\text {-last10 }}$ showed no trend, or even positive trends, in the depth range of $50 \pm 5 \mathrm{~m}$ and $100 \pm 5 \mathrm{~m}$ (Table 9). Sign of the TR $\mathrm{TR}_{\text {-last } 10}$ also changed to positive in the $200 \pm 5 \mathrm{~m}$ depth range of (a) Water temperature $[\operatorname{deg} \mathrm{C}]$ at $0 \mathrm{~m}$

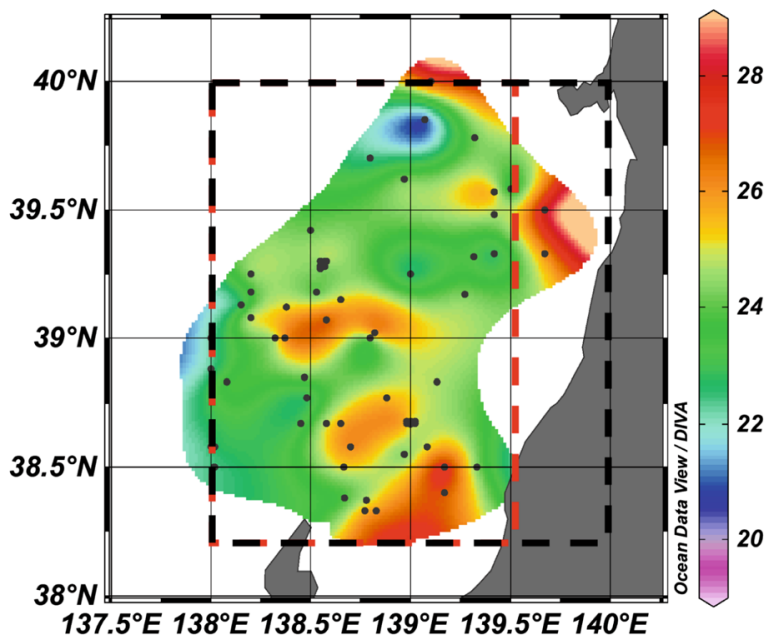

(b)

Salinity [psu] at $0 \mathrm{~m}$

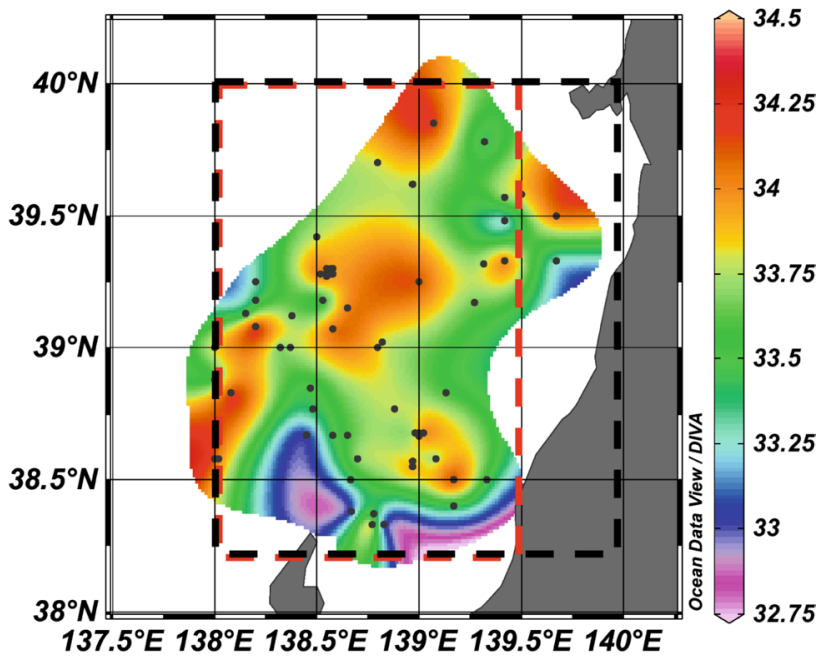

(c)

Oxygen $[\mu \mathrm{mol} / \mathrm{kg}]$ at $0 \mathrm{~m}$

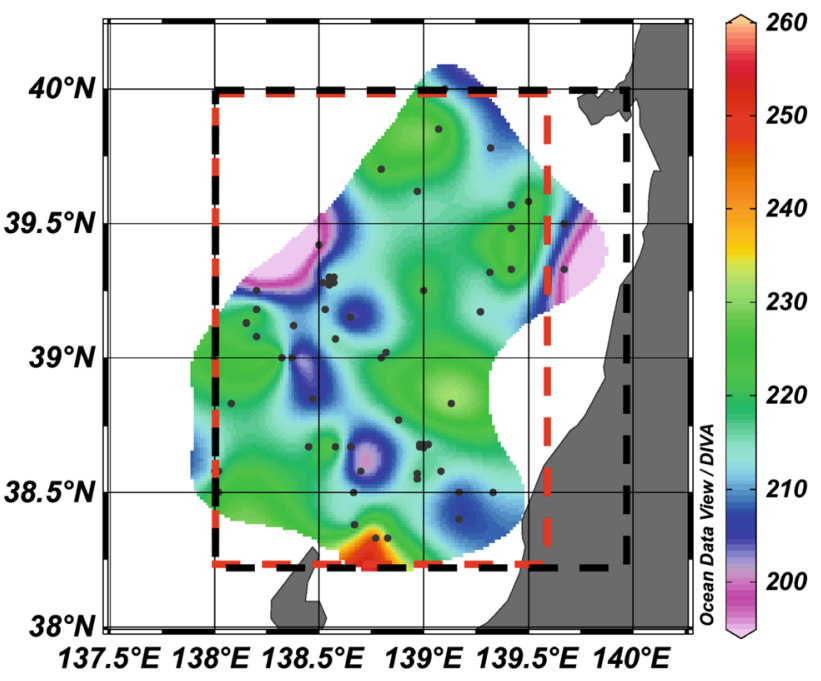


Fig. 8 Horizontal distribution of a water temperature, b salinity, and $\mathbf{c}$ dissolved oxygen on the $0 \mathrm{~m}$ isobaths in summer WB region. The meanings of black and red dashed line boxes were the same as those of Fig. 6. d-f The same as $(\mathbf{a}-\mathbf{c})$, but for the $0 \mathrm{~m}$ isobaths in winter WB (a)

Water temperature [deg C] at $0 \mathrm{~m}$

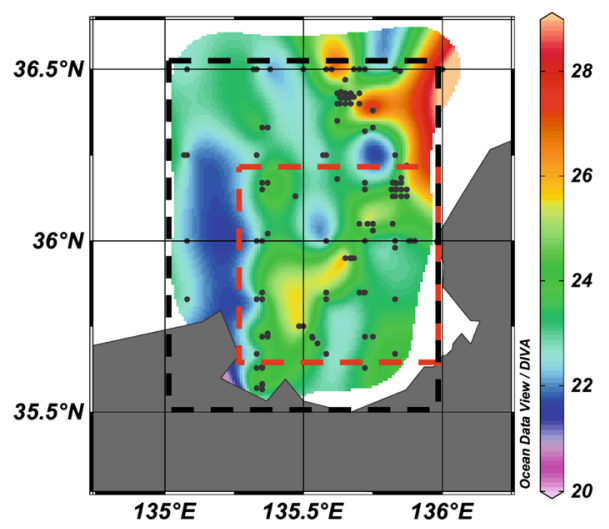

(b)

Salinity [psu] at $0 \mathrm{~m}$

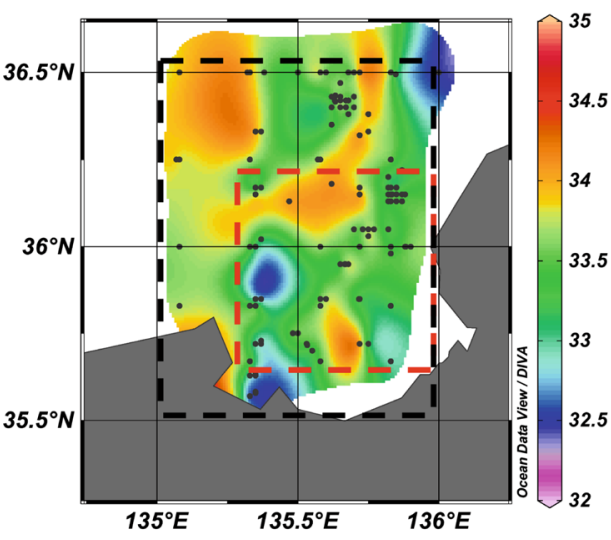

(c) Oxygen $[\mu \mathrm{mol} / \mathrm{kg}]$ at $0 \mathrm{~m}$

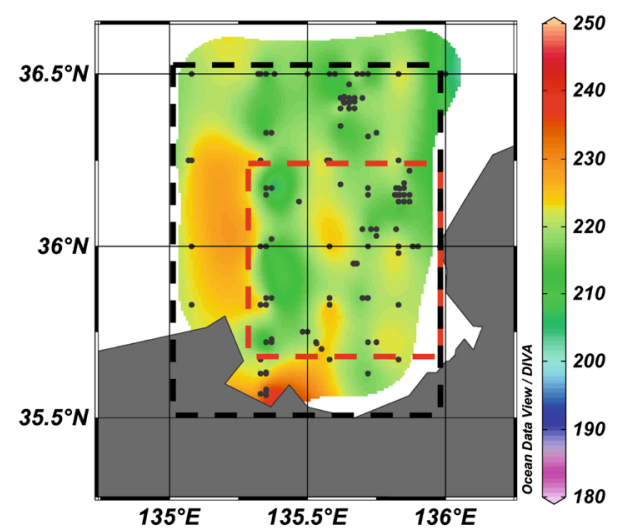

(d)

Water temperature [deg $\mathrm{C}]$ at $0 \mathrm{~m}$

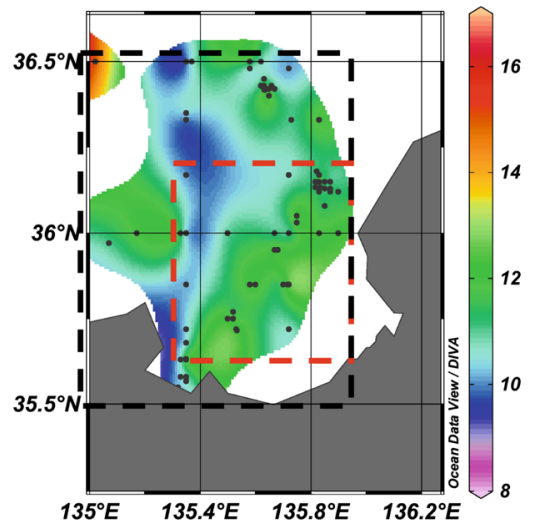

(e)

Salinity [psu] at $0 \mathrm{~m}$

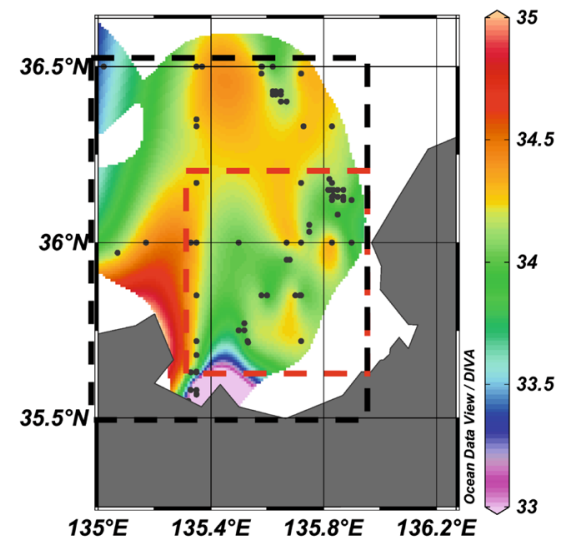

(f)

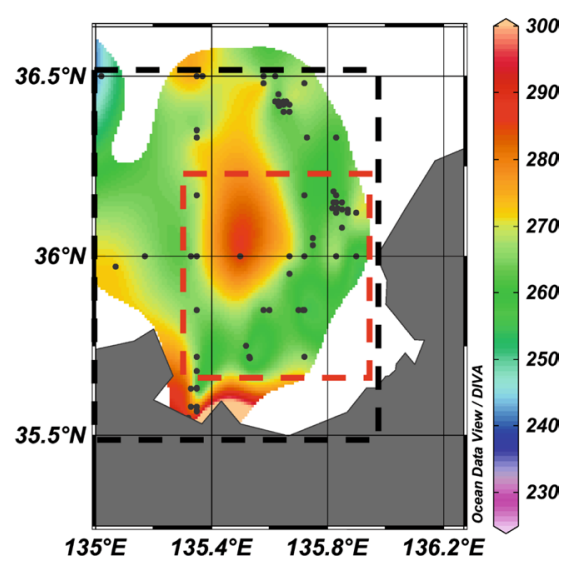



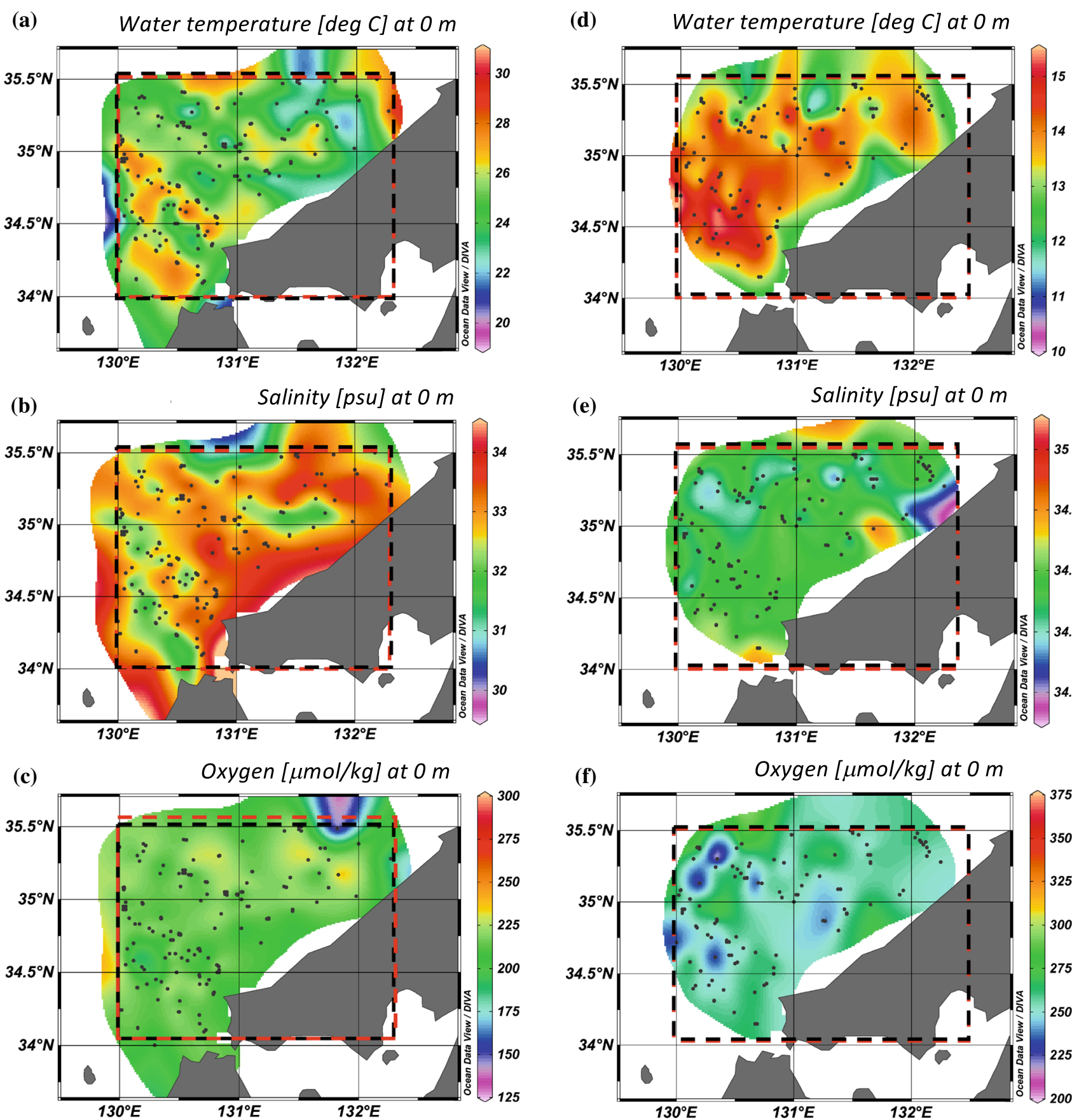

Fig. 9 Horizontal distribution of a water temperature, $\mathbf{b}$ salinity, and c dissolved oxygen on the $0 \mathrm{~m}$ isobaths in summer ETS region. The meanings of black and red dashed line boxes were same as those of Fig. 6. Note that the black and the red dashed line boxes were over-
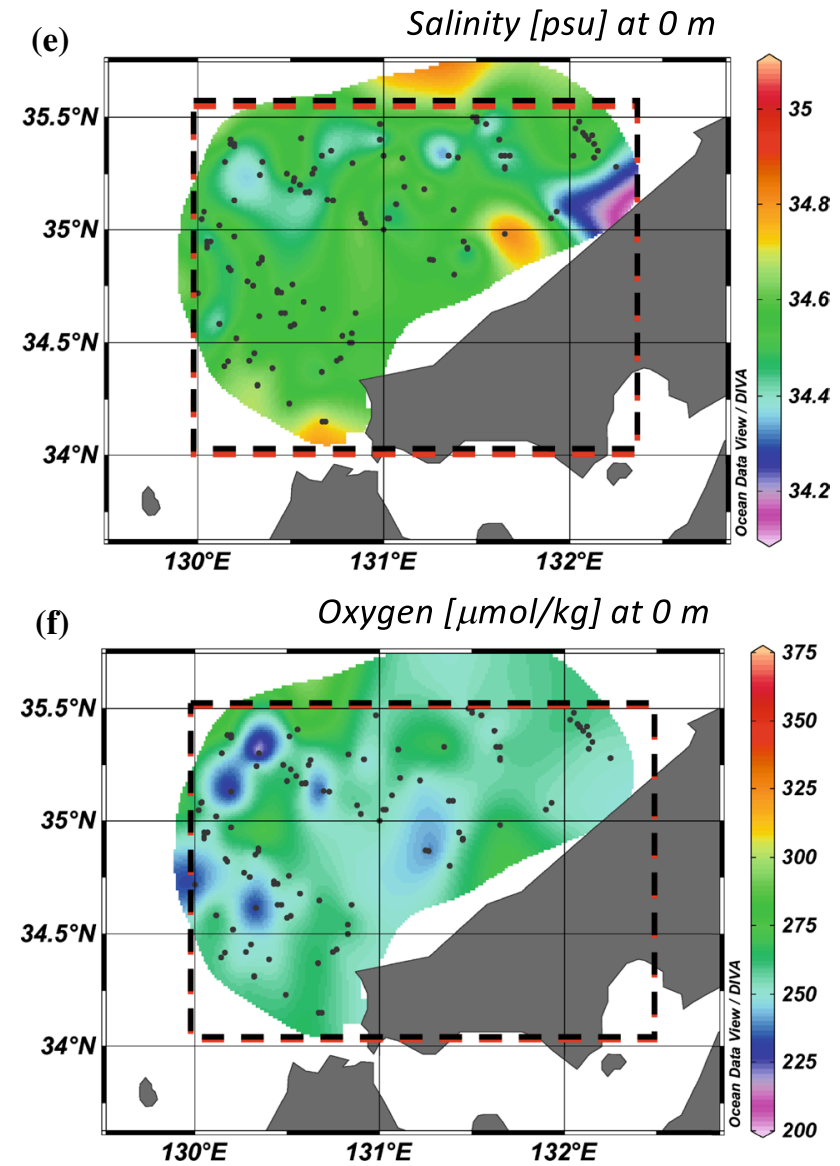

lapped in this figure, because no data were omitted by the horizontal homogeneity assessment for this region. $\mathbf{d}-\mathbf{f}$ Same as $(\mathbf{a}-\mathbf{c})$ but for the $0 \mathrm{~m}$ isobaths in winter ETS

Fig. 10 Time series of oxygen obtained in the depth ranges of a $0-1 \mathrm{~m}$, b $50 \pm 5 \mathrm{~m}$, c $100 \pm 5 \mathrm{~m}, \mathbf{d} 150 \pm 5 \mathrm{~m}$, e $200 \pm 5 \mathrm{~m}$, and f $300 \pm 5 \mathrm{~m}$ in summer, and $\mathbf{g} 0-1 \mathrm{~m}, \mathbf{h} 50 \pm 5 \mathrm{~m}, \mathbf{i} 100 \pm 5 \mathrm{~m}, \mathbf{j}$ $150 \pm 5 \mathrm{~m}, \mathbf{k} 200 \pm 5 \mathrm{~m}$, and $\mathbf{l} 300 \pm 5 \mathrm{~m}$ in winter, in YB. Solid lines indicate linear regressions in those statistically significant trend was observed, while dashed lines indicate ones with statistically insignificant trends 
Long-term trends of oxygen concentration in the waters in bank and shelves of the Southern Japan...

675
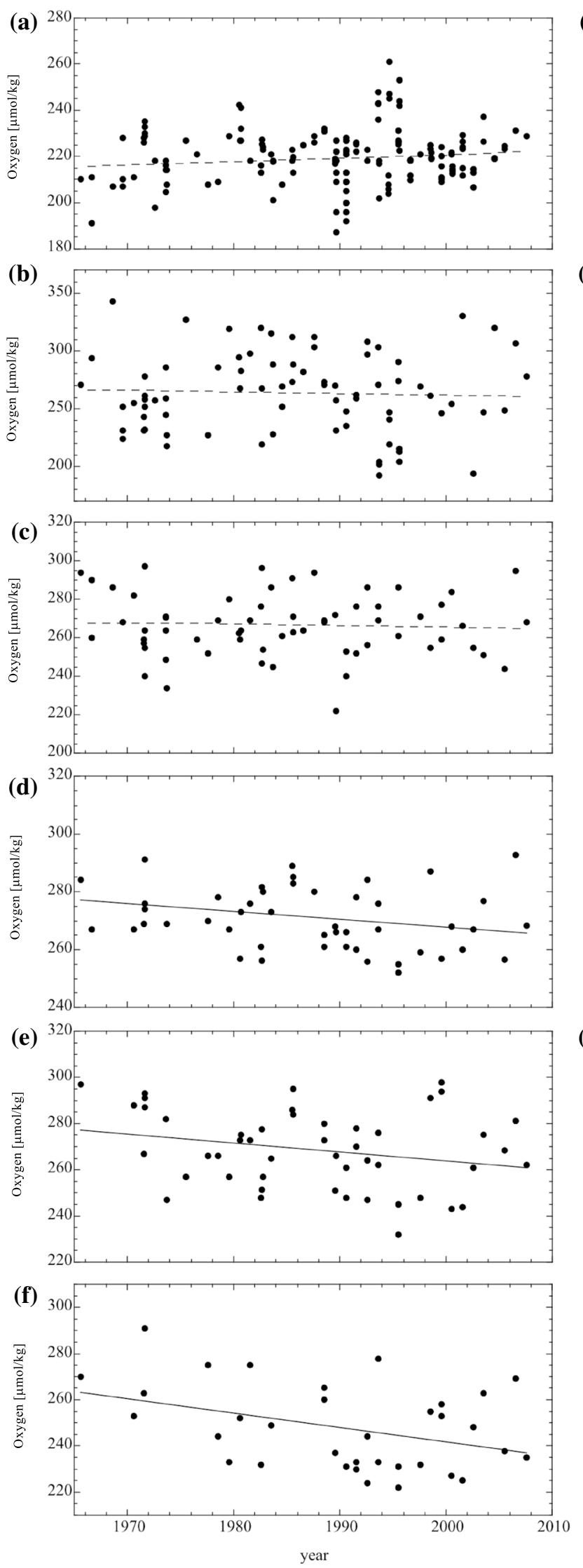
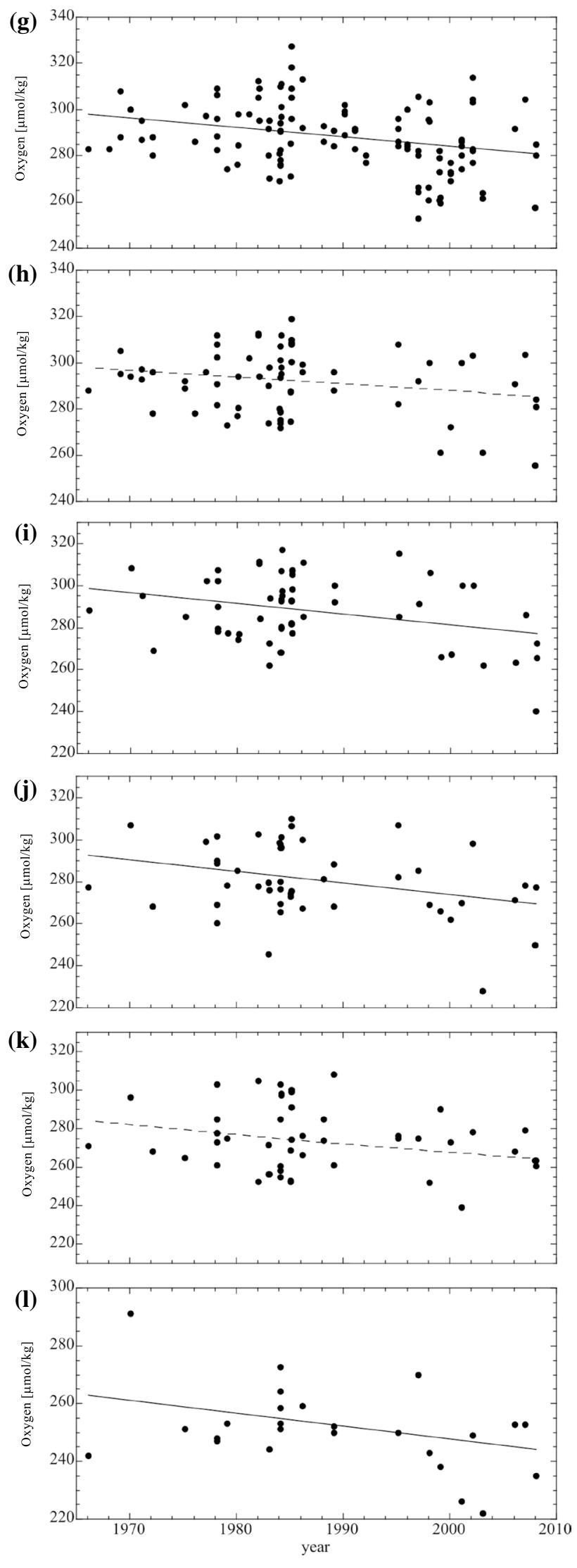

Springer 
Fig. 11 Time series of oxygen obtained in the depth ranges of a $0-1 \mathrm{~m}, \mathbf{b} 50 \pm 5 \mathrm{~m}, \mathbf{c} 100 \pm 5 \mathrm{~m}, \mathbf{d} 150 \pm 5 \mathrm{~m}$, e $200 \pm 5 \mathrm{~m}$, and f $300 \pm 5 \mathrm{~m}$ in summer AW

winter WB, although its statistical significance is almost neglectable. Minobe et al. (2004) made complex empirical orthogonal functions analyses of water temperature in the upper layers of Japan Sea, after the application of highpass filter with a cutoff period of seven years. They found that the amplitude of the first mode (CEOF-1), that was attributed to the meridional movement of polar front, was largest at the $100 \mathrm{~m}$ depth of YB area, and its time series indicate temporal cooling of water temperature in the latter half of 1980s. The amplitude of the second mode (CEOF-2) was largest at the area just north of WB in the depth range of 200-300 m, and its time series showed temporal cooling in early 1980s. Observed time series of CEOF-1 and CEOF-2 well corresponded the timing of oxygen increase observed in the $100 \mathrm{~m}$ isobaths of winter YB and the $200 \mathrm{~m}$ isobaths of winter WB, respectively (Figs. 4i and $6 \mathrm{j}$ in Appendix 2). Depth of maximum amplitude of CEOF-1 and CEOF-2 also corresponded to the isobaths where $\mathrm{TR}_{\text {-last10 }}$ showed positive trend in winter $\mathrm{YB}$ and $\mathrm{WB}$, respectively. These features indicated that positive $\mathrm{TR}_{\text {-last10 }}$ observed in several isobaths of winter $\mathrm{YB}$ and $\mathrm{WB}$ were the results of decadal-scale variation of $\mathrm{DO}_{\text {sol }}$ caused by local temporal variation of water temperature. We believe the existence of long-term negative trend of oxygen also in these areas and isobaths, but we could not estimate its rate because of the decadal-scale perturbation.
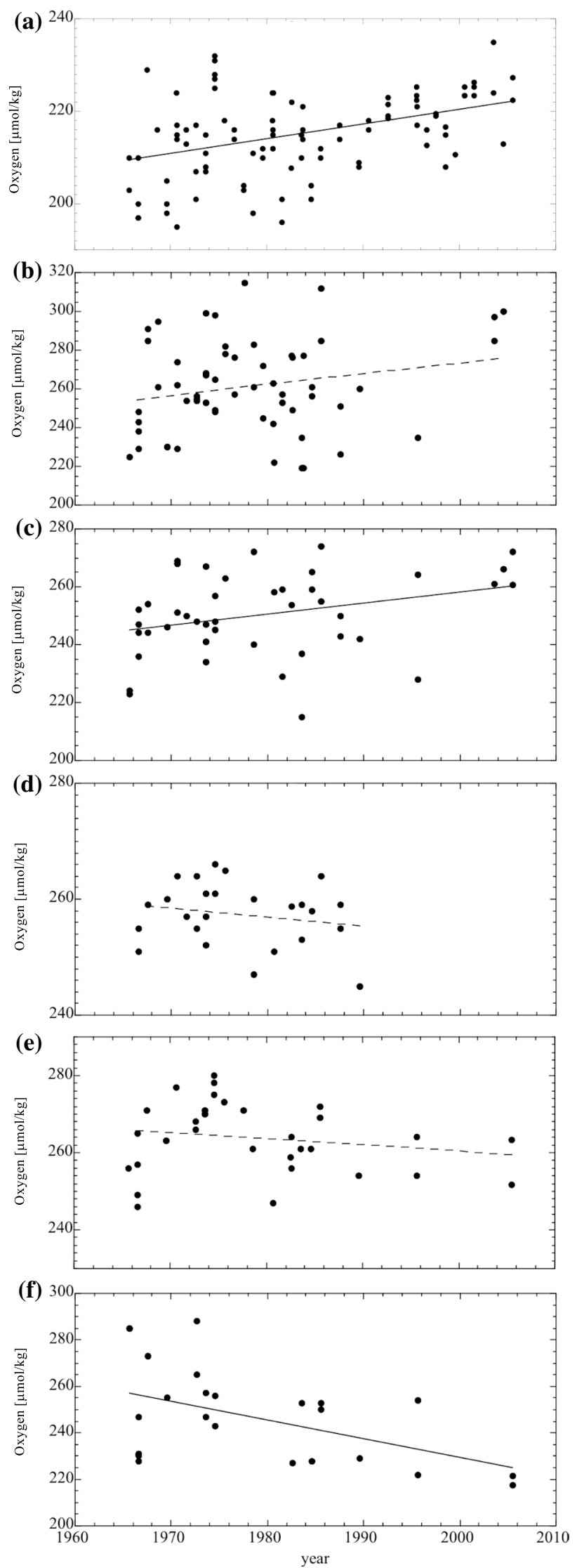

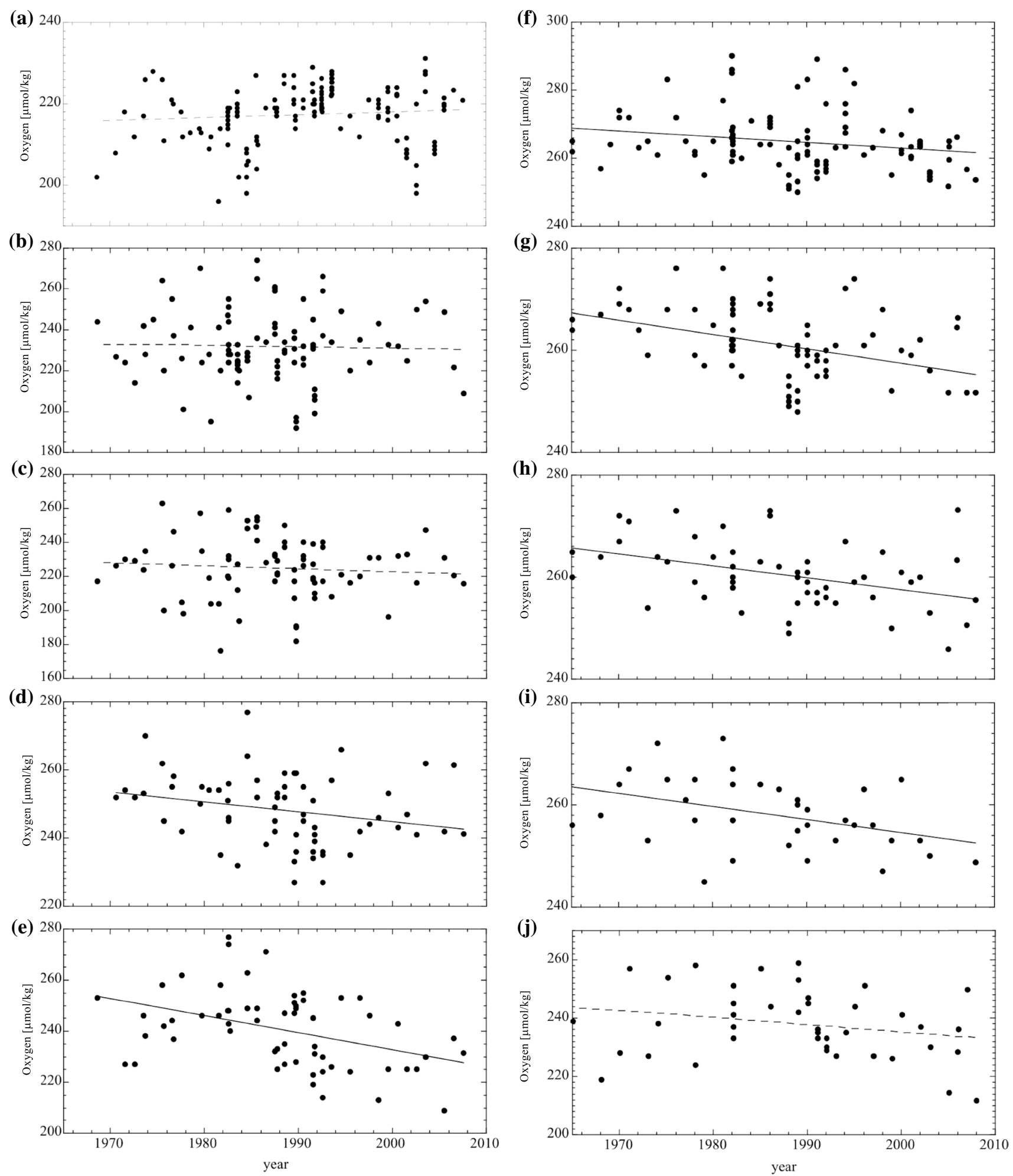

Fig. 12 Time series of oxygen obtained in the depth ranges of a $0-1 \mathrm{~m}, \mathbf{b} 50 \pm 5 \mathrm{~m}, \mathbf{c} 100 \pm 5 \mathrm{~m}, \mathbf{d} 150 \pm 5 \mathrm{~m}$, e $200 \pm 5 \mathrm{~m}$ in summer, and f $0-1 \mathrm{~m}, \mathbf{g} 50 \pm 5 \mathrm{~m}, \mathbf{h} 100 \pm 5 \mathrm{~m}, \mathbf{i} 150 \pm 5 \mathrm{~m}, \mathbf{j} 200 \pm 5 \mathrm{~m}$ in winter, in WB 
(a) 280
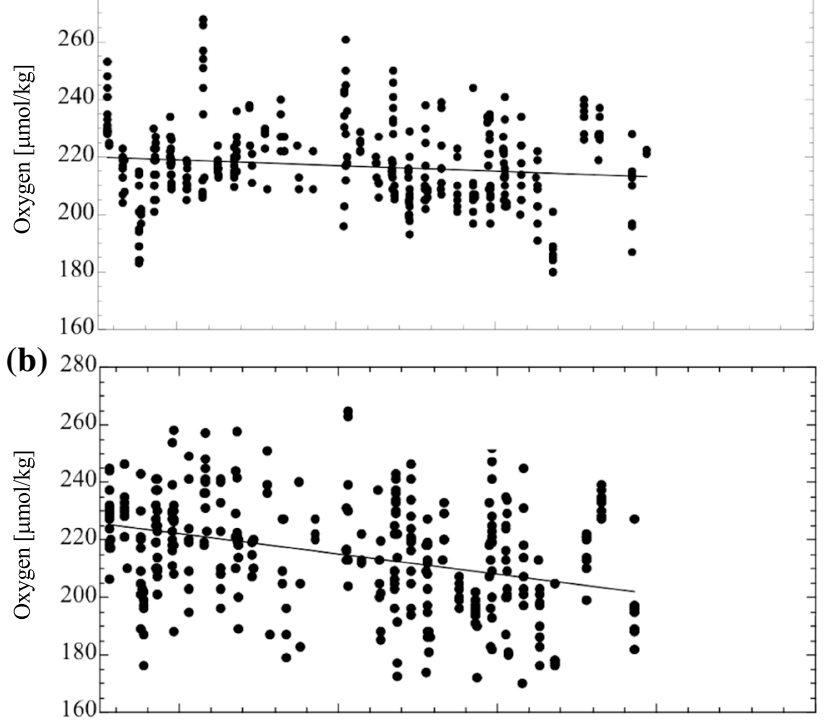

(c)

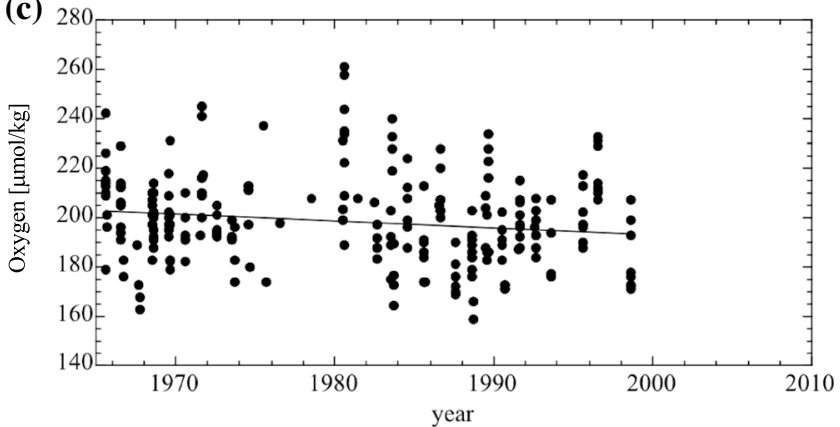

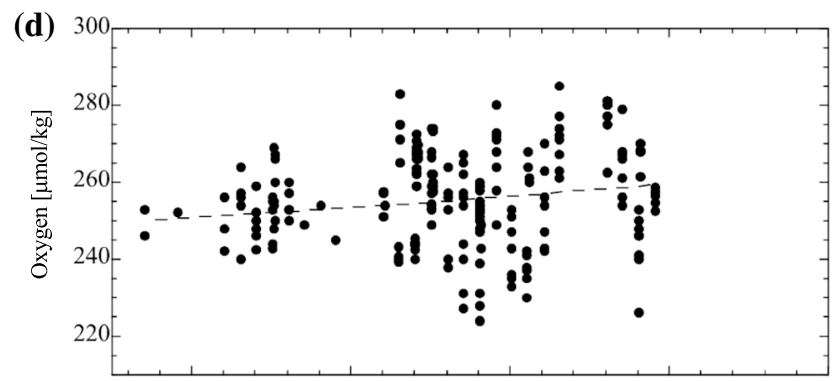

(e)

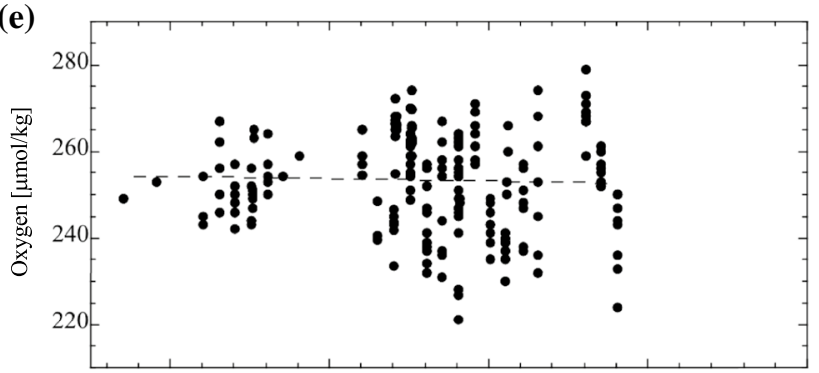

(f)

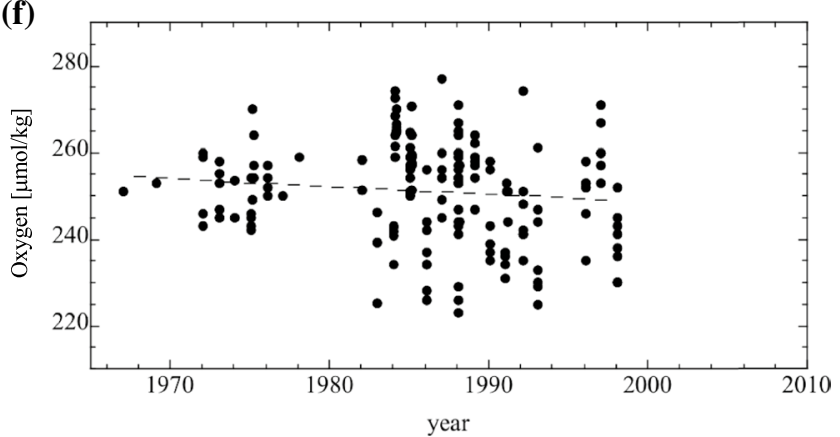

Fig. 13 Time series of oxygen obtained in the depth ranges of a $0-1 \mathrm{~m}, \mathbf{b} 50 \pm 5 \mathrm{~m}, \mathbf{c} 100 \pm 5 \mathrm{~m}$ in summer, and d $0-1 \mathrm{~m}$, e $50 \pm 5 \mathrm{~m}, \mathrm{f}$ ) $100 \pm 5 \mathrm{~m}$ in winter, in ETS

Table 4 Trends of oxygen in the waters deeper than $300 \mathrm{~m}$ in the study area $\left(\mu \mathrm{mol} \mathrm{kg} \mathrm{kg}^{-1} \cdot \mathrm{y}^{-1}\right)$

\begin{tabular}{lccc}
\hline Depth Range & Summer AW & Summer YB & Winter YB \\
\hline $400 \pm 10 \mathrm{~m}$ & $-0.53 \pm 0.19$ & $-0.51 \pm 0.19$ & $-0.72 \pm 0.17$ \\
$500 \pm 10 \mathrm{~m}$ & $-0.33 \pm 0.12$ & $-0.48 \pm 0.16$ & $-0.61 \pm 0.28$ \\
\hline
\end{tabular}

The data on isobaths of $400 \mathrm{~m}$ and $500 \mathrm{~m}$ were obtained from summer AW, summer YB, and winter YB, and trends were then calculated for each depth range, season and area. The plus-minus value represents $1 \mathrm{SD}$ 

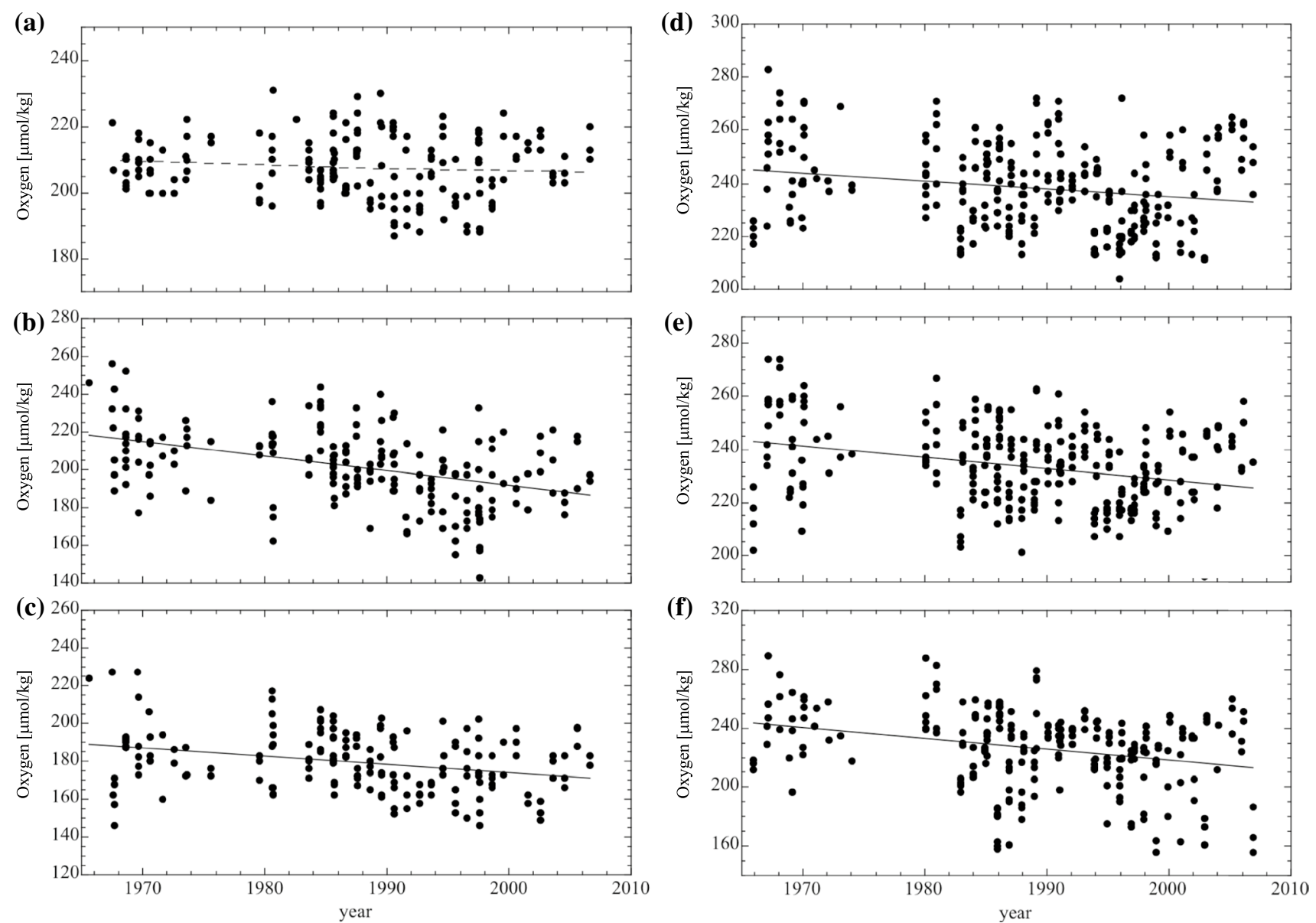

Fig. 14 Time series of oxygen obtained in the depth ranges of a $0-1 \mathrm{~m}, \mathbf{b} 50 \pm 5 \mathrm{~m}, \mathbf{c} 100 \pm 5 \mathrm{~m}$ in summer, and d $0-1 \mathrm{~m}, \mathbf{e} 50 \pm 5 \mathrm{~m}, \mathbf{f} 100 \pm 5 \mathrm{~m}$ in winter, in WTS

Table 5 The same as in Table 2, but for WTS region

\begin{tabular}{lll}
\hline Depth Range & WTS & WTS \\
& Summer & Winter \\
\hline$[0-1 \mathrm{~m}]$ & & \\
Temp & $0.00 \pm 0.01$ & $\mathbf{0 . 0 5} \pm \mathbf{0 . 0 1}$ \\
Sal & $-0.015 \pm 0.008$ & $-\mathbf{0 . 0 1 4} \pm \mathbf{0 . 0 0 2}$ \\
$\mathrm{DO}$ & $-0.08 \pm 0.06$ & $-\mathbf{0 . 2 9} \pm \mathbf{0 . 0 9}$ \\
$\mathrm{DO}$ & $-0.02 \pm 0.06$ & $-\mathbf{0 . 2 4} \pm \mathbf{0 . 0 7}$ \\
{$[50 \pm 3 \mathrm{~m}]$} & & \\
Temp & $-0.07 \pm 0.02$ & $\mathbf{0 . 0 5} \pm \mathbf{0 . 0 1}$ \\
$\mathrm{Sal}$ & $-0.003 \pm 0.003$ & $-\mathbf{0 . 0 0 6} \pm \mathbf{0 . 0 0 2}$ \\
$\mathrm{DO}$ & $-\mathbf{0 . 7 7} \pm \mathbf{0 . 1 1}$ & $-\mathbf{0 . 4 3} \pm \mathbf{0 . 0 9}$ \\
$\mathrm{DO}$ & & $-\mathbf{0 . 2 4} \pm \mathbf{0 . 0 7}$ \\
{$[100 \pm 5 \mathrm{~m}]$} & $\mathbf{0 . 3 2} \pm \mathbf{0 . 0 8}$ & \\
Temp & & $\mathbf{0 . 0 3} \pm \mathbf{0 . 0 1}$ \\
Sal & $-\mathbf{0 . 0 2} \pm \mathbf{0 . 0 1}$ & $-\mathbf{0 . 0 0 7} \pm \mathbf{0 . 0 0 1}$ \\
$\mathrm{DO}$ & $0.002 \pm 0.002$ & $-\mathbf{0 . 7 2} \pm \mathbf{0 . 0 2}$ \\
$\mathrm{DO}$ & $-\mathbf{0 . 4 1} \pm \mathbf{0 . 1 1}$ & $-0.12 \pm 0.07$ \\
\hline
\end{tabular}


Table 6 List of average \pm 2 SD of oxygen concentration in 1960 $\left(\mathrm{DO}_{1960}, \mu \mathrm{mol} \mathrm{kg}{ }^{-1}\right)$, estimated year of emergence referred from $1960\left(\mathrm{YoE}_{1960}\right)$, and year of threshold (YoT), in each area and for each depth range in summer

\begin{tabular}{|c|c|c|c|c|c|}
\hline Depth Range & WTS & ETS & WB & AW & YB \\
\hline \multicolumn{6}{|l|}{$[0-1 \mathrm{~m}]$} \\
\hline $\mathrm{DO}_{1960}$ & & $221 \pm 30$ & & & \\
\hline $\mathrm{YoE}_{1960}$ by $\mathrm{TR}_{\text {ful }}$ & & 2115 & & & \\
\hline Range & & $2035-2315$ & & & \\
\hline YoT by $\mathrm{TR}_{\text {ful }}$ & & 2406 & & & \\
\hline Range & & $2140-3011$ & & & \\
\hline \multicolumn{6}{|l|}{$[50 \pm 3 \mathrm{~m}]$} \\
\hline $\mathrm{DO}_{1960}$ & $223 \pm 36$ & $229 \pm 37$ & & & \\
\hline $\mathrm{YoE}_{1960}$ by $\mathrm{TR}_{\text {ful }}$ & 2006 & 2013 & & & \\
\hline Range & 2003-2006 & 2008-2023 & & & \\
\hline YoT by $\mathrm{TR}_{\text {ful }}$ & 2078 & 2094 & & & \\
\hline Range & 2060-2078 & 2076-2124 & & & \\
\hline \multicolumn{6}{|l|}{$[100 \pm 5 \mathrm{~m}]$} \\
\hline $\mathrm{DO}_{1960}$ & $191 \pm 31$ & $205 \pm 35$ & & & \\
\hline $\mathrm{YoE}_{1960}$ by $\mathrm{TR}_{\text {ful }}$ & 2034 & 2072 & & & \\
\hline Range & 2022-2034 & 2020-2072 & & & \\
\hline YoT by $\mathrm{TR}_{\text {ful }}$ & 2098 & 2185 & & & \\
\hline Range & 2065-2098 & 2060-2185 & & & \\
\hline \multicolumn{6}{|l|}{$[150 \pm 5 \mathrm{~m}]$} \\
\hline $\mathrm{DO}_{1960}$ & & & $256 \pm 20$ & & $278 \pm 23$ \\
\hline $\mathrm{YoE}_{1960}$ by $\mathrm{TR}_{\text {ful }}$ & & & 2029 & & 2025 \\
\hline Range & & & 2006-2057 & & 2013-2025 \\
\hline YoT by $\mathrm{TR}_{\text {ful }}$ & & & 2379 & & 2440 \\
\hline Range & & & $2182-2682$ & & $2320-2440$ \\
\hline \multicolumn{6}{|l|}{$[200 \pm 5 \mathrm{~m}]$} \\
\hline $\mathrm{DO}_{1960}$ & & & $259 \pm 27$ & & $280 \pm 32$ \\
\hline $\mathrm{YoE}_{1960}$ by $\mathrm{TR}_{\text {ful }}$ & & & 2001 & & 2029 \\
\hline Range & & & 1997-2009 & & $2002-2170$ \\
\hline YoT by $\mathrm{TR}_{\text {ful }}$ & & & 2146 & & 2277 \\
\hline Range & & & $2080-2223$ & & 2121-3434 \\
\hline \multicolumn{6}{|l|}{$[300 \pm 5 \mathrm{~m}]$} \\
\hline $\mathrm{DO}_{1960}$ & & & & $261 \pm 35$ & $266 \pm 42$ \\
\hline $\mathrm{YoE}_{1960}$ by $\mathrm{TR}_{\text {ful }}$ & & & & 2004 & 2015 \\
\hline Range & & & & 2002-2012 & 1997-2039 \\
\hline YoT by $\mathrm{TR}_{\text {ful }}$ & & & & 2119 & 2172 \\
\hline Range & & & & 2104-2158 & 2073-2396 \\
\hline
\end{tabular}

$\mathrm{YoE}_{1960}$ and YoT were estimated from $\mathrm{TR}_{\text {full }}$ (Appendix 3), while range of three estimations based on $\mathrm{TR}_{\text {full }}, \mathrm{TR}_{\text {-last10 }}$, and $\mathrm{TR}_{\text {-first10 }}$ are additionally listed. Calculations were omitted where $\mathrm{TR}_{\text {full }}$ was not negative with statistical significance, and were also omitted where either $\mathrm{TR}_{\text {-last10 }}$ or $\mathrm{TR}_{\text {-first10 }}$ became positive regardless of its statistical significance. Bold numbers indicate that waters which had already reached to YoE $_{1960}$ 
Table 7 The same as in Table 6, but for winter data. AW is omitted, similarly to Table 3

\begin{tabular}{|c|c|c|c|c|}
\hline Depth Range & WTS & ETS & WB & YB \\
\hline \multicolumn{5}{|l|}{$[0-1 \mathrm{~m}]$} \\
\hline $\mathrm{DO}_{1960}$ & $247 \pm 31$ & & $270 \pm 18$ & $302 \pm 27$ \\
\hline YoE $_{1960}$ by $\mathrm{TR}_{\text {ful }}$ & 2065 & & 2071 & 2014 \\
\hline Range & $2027-2115$ & & $2045-2149$ & 2010-2027 \\
\hline YoT by $\mathrm{TR}_{\mathrm{ful}}$ & 2342 & & 2786 & 2296 \\
\hline Range & $2180-2590$ & & $2527-3494$ & $2220-2403$ \\
\hline \multicolumn{5}{|l|}{$[50 \pm 3 \mathrm{~m}]$} \\
\hline $\mathrm{DO}_{1960}$ & $246 \pm 30$ & & $269 \pm 13$ & \\
\hline YoE $_{1960}$ by $\mathrm{TR}_{\text {ful }}$ & 2030 & & 2005 & \\
\hline Range & 2018-2034 & & 2001-2006 & \\
\hline YoT by $\mathrm{TR}_{\mathrm{ful}}$ & 2220 & & 2438 & \\
\hline Range & $2160-2244$ & & $2370-2463$ & \\
\hline \multicolumn{5}{|l|}{$[100 \pm 5 \mathrm{~m}]$} \\
\hline $\mathrm{DO}_{1960}$ & $247 \pm 50$ & & $267 \pm 12$ & \\
\hline YoE $_{1960}$ by $\mathrm{TR}_{\text {ful }}$ & 2029 & & 2012 & \\
\hline Range & $2022-2029$ & & 2008-2012 & \\
\hline YoT by $\mathrm{TR}_{\text {ful }}$ & 2116 & & 2535 & \\
\hline Range & 2096-2118 & & $2464-2535$ & \\
\hline \multicolumn{5}{|l|}{$[150 \pm 5 \mathrm{~m}]$} \\
\hline $\mathrm{DO}_{1960}$ & & & $265 \pm 13$ & $294 \pm 29$ \\
\hline $\mathrm{YoE}_{1960}$ by $\mathrm{TR}_{\text {ful }}$ & & & 2010 & 2028 \\
\hline Range & & & 2006-2011 & $2021-3451$ \\
\hline YoT by $\mathrm{TR}_{\text {ful }}$ & & & 2470 & 2337 \\
\hline Range & & & $2383-2503$ & $2271-13,204$ \\
\hline \multicolumn{5}{|l|}{$[200 \pm 5 \mathrm{~m}]$} \\
\hline \multicolumn{5}{|l|}{$\mathrm{DO}_{1960}$} \\
\hline \multicolumn{5}{|l|}{$\mathrm{YoE}_{1960}$ by $\mathrm{TR}_{\text {ful }}$} \\
\hline \multicolumn{5}{|l|}{ Range } \\
\hline \multicolumn{5}{|l|}{ YoT by $\mathrm{TR}_{\text {ful }}$} \\
\hline \multicolumn{5}{|l|}{ Range } \\
\hline \multicolumn{5}{|l|}{$[300 \pm 5 \mathrm{~m}]$} \\
\hline $\mathrm{DO}_{1960}$ & & & & $266 \pm 30$ \\
\hline $\mathrm{YoE}_{1960}$ by $\mathrm{TR}_{\text {ful }}$ & & & & 2028 \\
\hline range & & & & 2012-2093 \\
\hline YoT by $\mathrm{TR}_{\mathrm{ful}}$ & & & & 2254 \\
\hline Range & & & & $2237-2821$ \\
\hline
\end{tabular}


Table 8 List of $\mathrm{TR}_{\text {full }}, \mathrm{TR}_{\text {-last10 }}$, and $\mathrm{TR}_{\text {-first } 10}$ in each reference depth range in each study area in summer season $(\mu \mathrm{mol}$ $\left.\mathrm{kg}^{-1} \cdot \mathrm{y}^{-1}\right)$

\begin{tabular}{|c|c|c|c|c|c|}
\hline Depth Range & WTS & ETS & WB & AW & YB \\
\hline \multicolumn{6}{|l|}{$[0-1 \mathrm{~m}]$} \\
\hline $\mathrm{TR}_{\text {full }}$ & $-0.08 \pm 0.06$ & $-0.19 \pm 0.08$ & & & \\
\hline $\mathrm{TR}_{\text {-last10 }}$ & $-0.19 \pm 0.09$ & $-0.08 \pm 0.10$ & & & \\
\hline $\mathrm{TR}_{\text {-first10 }}$ & $-0.06 \pm 0.12$ & $-0.53 \pm 0.17$ & & & \\
\hline \multicolumn{6}{|l|}{$[50 \pm 3 \mathrm{~m}]$} \\
\hline $\mathrm{TR}_{\text {full }}$ & $-0.75 \pm 0.12$ & $-0.70 \pm 0.10$ & & & \\
\hline $\mathrm{TR}_{\text {-last } 10}$ & $-0.91 \pm 0.15$ & $-0.57 \pm 0.13$ & & & \\
\hline $\mathrm{TR}_{\text {-first10 }}$ & $-0.80 \pm 0.20$ & $-0.84 \pm 0.25$ & & & \\
\hline \multicolumn{6}{|l|}{$[100 \pm 5 \mathrm{~m}]$} \\
\hline $\mathrm{TR}_{\text {full }}$ & $-0.41 \pm 0.11$ & $-0.31 \pm 0.10$ & & & \\
\hline $\mathrm{TR}_{\text {-last10 }}$ & $-0.49 \pm 0.14$ & $-0.39 \pm 0.17$ & & & \\
\hline $\mathrm{TR}_{\text {-first } 10}$ & $-0.59 \pm 0.17$ & $-0.87 \pm 0.29$ & & & \\
\hline \multicolumn{6}{|l|}{$[150 \pm 5 \mathrm{~m}]$} \\
\hline $\mathrm{TR}_{\text {full }}$ & & & $-0.29 \pm 0.14$ & & $-0.30 \pm 0.14$ \\
\hline $\mathrm{TR}_{\text {-last } 10}$ & & & $-0.58 \pm 0.20$ & & $-0.40 \pm 0.18$ \\
\hline $\mathrm{TR}_{\text {-first10 }}$ & & & $-0.16 \pm 0.20$ & & $-0.32 \pm 0.20$ \\
\hline \multicolumn{6}{|l|}{$[200 \pm 5 \mathrm{~m}]$} \\
\hline $\mathrm{TR}_{\text {full }}$ & & & $-0.67 \pm 0.19$ & $-0.16 \pm 0.15$ & $-0.46 \pm 0.21$ \\
\hline $\mathrm{TR}_{\text {-last10 }}$ & & & $-0.46 \pm 0.27$ & $-0.11 \pm 0.20$ & $-0.97 \pm 0.28$ \\
\hline $\mathrm{TR}_{\text {-first10 }}$ & & & $-1.18 \pm 0.26$ & $-0.26 \pm 0.21$ & $-0.01 \pm 0.29$ \\
\hline \multicolumn{6}{|l|}{$[300 \pm 5 \mathrm{~m}]$} \\
\hline $\mathrm{TR}_{\text {full }}$ & & & & $-0.80 \pm 0.30$ & $-0.62 \pm 0.27$ \\
\hline $\mathrm{TR}_{\text {-last10 }}$ & & & & $-0.63 \pm 0.42$ & $-1.27 \pm 0.37$ \\
\hline $\mathrm{TR}_{\text {-first10 }}$ & & & & $-0.89 \pm 0.52$ & $-0.27 \pm 0.36$ \\
\hline
\end{tabular}

Calculations were made only for the data for which $\mathrm{TR}_{\text {full }}$ was negative and its absolute value was larger than 1SD in Table 2. The plus-minus value represents 1SD. Bold font indicates the trends which have statistical significance with $p$ value less than 0.05

Table 9 The same as in Table 8, but for winter data

\begin{tabular}{|c|c|c|c|c|}
\hline Depth Range & WTS & ETS & WB & YB \\
\hline \multicolumn{5}{|l|}{$[0-1 \mathrm{~m}]$} \\
\hline $\mathrm{TR}_{\text {full }}$ & $-0.29 \pm 0.09$ & & $-0.16 \pm 0.08$ & $-0.50 \pm 0.12$ \\
\hline $\mathrm{TR}_{\text {-last10 }}$ & $-0.53 \pm 0.11$ & & $-0.08 \pm 0.14$ & $-0.37 \pm 0.17$ \\
\hline $\begin{array}{l}\mathrm{TR}_{\text {-first10 }} \\
{[50 \pm 3 \mathrm{~m}]}\end{array}$ & $-0.17 \pm 0.14$ & & $-0.24 \pm 0.11$ & $-0.67 \pm 0.15$ \\
\hline $\mathrm{TR}_{\text {full }}$ & $-0.43 \pm 0.09$ & & $-0.28 \pm 0.08$ & $-0.29 \pm 0.16$ \\
\hline $\mathrm{TR}_{\text {-last } 10}$ & $-0.57 \pm 0.11$ & & $-0.33 \pm 0.10$ & $0.11 \pm 0.25$ \\
\hline $\begin{array}{l}\mathrm{TR}_{-\mathrm{first}} 10 \\
{[100 \pm 5 \mathrm{~m}]}\end{array}$ & $-0.39 \pm 0.13$ & & $-0.27 \pm 0.11$ & $-0.36 \pm 0.20$ \\
\hline $\mathrm{TR}_{\text {full }}$ & $-0.72 \pm 0.16$ & & $-0.23 \pm 0.07$ & $-0.50 \pm 0.21$ \\
\hline $\mathrm{TR}_{\text {-last10 }}$ & $-0.85 \pm 0.19$ & & $-0.26 \pm 0.09$ & $0.39 \pm 0.33$ \\
\hline $\begin{array}{l}\mathrm{TR}_{\text {first10 }} \\
{[150 \pm 5 \mathrm{~m}]}\end{array}$ & $-0.71 \pm 0.24$ & & $-0.23 \pm 0.10$ & $-0.61 \pm 0.24$ \\
\hline $\mathrm{TR}_{\text {full }}$ & & & $-0.26 \pm 0.10$ & $-0.42 \pm 0.21$ \\
\hline $\mathrm{TR}_{\text {-last10 }}$ & & & $-0.24 \pm 0.13$ & $-0.01 \pm 0.35$ \\
\hline $\begin{array}{l}\mathrm{TR}_{\text {first10 }} \\
{[200 \pm 5 \mathrm{~m}]}\end{array}$ & & & $-0.31 \pm 0.13$ & $-0.52 \pm 0.24$ \\
\hline $\mathrm{TR}_{\text {full }}$ & & & $-0.24 \pm 0.16$ & $-0.33 \pm 0.24$ \\
\hline $\mathrm{TR}_{\text {-last } 10}$ & & & $0.03 \pm 0.22$ & $-0.20 \pm 0.42$ \\
\hline $\begin{array}{l}\mathrm{TR}_{-\mathrm{first}} 10 \\
{[300 \pm 5 \mathrm{~m}]}\end{array}$ & & & $-0.63 \pm 0.20$ & $-0.43 \pm 0.28$ \\
\hline $\mathrm{TR}_{\text {full }}$ & & & & $-0.51 \pm 0.23$ \\
\hline $\mathrm{TR}_{\text {-last10 }}$ & & & & $-0.14 \pm 0.36$ \\
\hline $\mathrm{TR}_{\text {-first10 }}$ & & & & $-0.47 \pm 0.23$ \\
\hline
\end{tabular}


Acknowledgments I thank all the crew members, research scientists, and data managers who worked to produce the broad data used in this study. I also appreciate two anonymous reviewers for variable comments and discussions. This study was funded both by JSPS KAKENHI Grant Number JP 18H04129 and Study of Biological Effects of Acidification and Hypoxia (BEACH) of the Environment Research and Technology Development Fund Grant Number JPMEERF20202007 of the Environmental Restoration and Conservation Agency of Japan.

Open Access This article is licensed under a Creative Commons Attribution 4.0 International License, which permits use, sharing, adaptation, distribution and reproduction in any medium or format, as long as you give appropriate credit to the original author(s) and the source, provide a link to the Creative Commons licence, and indicate if changes were made. The images or other third party material in this article are included in the article's Creative Commons licence, unless indicated otherwise in a credit line to the material. If material is not included in the article's Creative Commons licence and your intended use is not permitted by statutory regulation or exceeds the permitted use, you will need to obtain permission directly from the copyright holder. To view a copy of this licence, visit http://creativecommons.org/licenses/by/4.0/.

\section{References}

Boyer TP, Baranova OK, Coleman, C, Garcia HE, Grodsky A, Locarnini RA, Mishonov AV, Paver CR, Reagan JR, Seidov D, Smolyar IV, Weathers KW, Zweng MM (2018) World Ocean Database 2018. Mishonov AV, Technical Ed. NOAA Atlas NESDIS87. https://www.nodc.noaa.gov/OC5/WOD/pr_wod.html

Chabot D, Claireaux G (2008) Environmental hypoxia as a metabolic constraint on fish: The case of Atlantic cod, Gadus morhua. Mar Poll Bull 57:287-294. https://doi.org/10.1016/j.marpo lbul.2008.04.001

Chen C-TA, Bychkov AS, Wang SL, Pavlova GY (1999) An anoxic Sea of Japan by the year 2200? Mar Chem 67:249-265. https://doi. org/10.1016/S0304-4203(99)00074-2

Chen C-TA, Lui H-K, Hsieh C-H, Yanagi T, Kosugi N, Ishii M, Gong G-C (2017) Deep oceans may acidify faster than anticipated due to global warming. Nat Clim Change 7:890-894. https://doi. org/10.1038/s41558-017-0003-y

Cho Y-K, Kim K (1998) Structure of the Korea Strait Bottom Cold Water and its seasonal variation in 1991. Cont Shelf Res 18:791-804

Gamo T (1999) Global warming may have slowed down the deep conveyor belt of a marginal sea of the northwestern Pacific: Japan Sea. Geophys Res Lett 26:3141-3144. https://doi.org/10.1029/1999G L002341

Gamo T (2011) Dissolved oxygen in the bottom water of the Sea of Japan as a sensitive alarm for global climate change. TrAC Trends Anal Chem 30:1308-1319. https://doi.org/10.1016/j. trac.2011.06.005

Gamo T, Nozaki Y, Sakai H, Nakai T, Tsubota H (1986) Spatial and temporal variations of water characteristics in the Japan Sea bottom layer. J Mar Res 44:781-793

Gamo T, Momoshima N, Tolmachoyov S (2001) Recent upward shift of the deep convection system in the Japan Sea, as inferred from the geochemical tracers tritium, oxygen, and nutrients. Geophys Res Lett 28:4143-4146. https://doi.org/10.1029/2001GL013367

Gamo T, Nakayama N, Takahata N, Sano Y, Zhang J, Yamazaki E, Taniyasu S, Yamashita N (2014) The Sea of Japan and its unique chemistry revealed by time-series observations over the last 30 years. Monogr Environ Earth Planets 2:1-22. https://doi. org/10.5047/meep.2014.00201.0001
Giorgi F, Bi X (2009) Time of emergence (TOE) of GHG- forced precipitation change hot-spots. Geophys Res Lett 36:L06709. https ://doi.org/10.1029/2009GL037593

Hase H, Yoon J-H, Koterayama W (1999) The current structure of the Tsushima Warm Current along the Japanese coast. J Oceanogr 55:217-235. https://doi.org/10.1023/A:1007894030095

Helm KP, Bindoff NL, Church JA (2011) Observed decreases in oxygen content of the global ocean. Geophys Res Lett 38:L23602. https ://doi.org/10.1029/2011GL049513

IPCC (2013) Climate Change 2013: The Physical Science Basis. Contributing Working Group 1 to the Fifth Assessment Report of the Intergovernmental Panel on Climate Change. Cambridge University Press, Cambridge, United Kingdom and New York, NY, USA, p 1535

IPCC (2019) IPCC Special Report on the Ocean and Cryosphere in a Changing Climate. In Press.

Isobe A (1995) The influence of the Bottom Cold Water on the seasonal variability of the Tsushima Warm Current. Cont Shelf Res 15:763-777. https://doi.org/10.1016/0278-4343(94)00047-Q

Ishizaka J, Yamada K (2019) Phytoplankton and primary production in the japan Sea. In: Barale V, Gade M (eds) Remote sensing of the Asian Seas. Springer, Cham, pp 177-189. https://doi. org/10.1007/978-3-319-94067-0_9

Ito T, Minobe S, Long MC, Deutch C (2017) Upper ocean $\mathrm{O}_{2}$ trends: 1958-2015. Geophys Res Lett 44:4214-4223. https://doi. org/10.1002/2017GL073613

Joyce TM (1991) Introduction to the collection of expert reports compiled for the WHP program. WOCE Hydrographic operations and methods, WOCE Operations Manual, WHP Office Rep. WHPO91-1, WOCE Rep. 68/91, 4 pp.

Kawabe K (1982) Branching of the Tsushima current in the Japan Sea Part 1. Data Analysis. J Oceanogr 38:95-107. https://doi. org/10.1007/BF02110295

Keller KM, Joos F, Raible CC (2014) Time of emergence of trends in ocean biogeochemistry. Biogeosci 11:3647-3659. https://doi. org/10.5194/bg-11-3647-2014

Kim H, Takayama K, Hirose N, Onitsuka G, Yoshida T, Yanagi T (2019) Biological modulation in the seasonal variation of dissolved oxygen concentration in the upper Japan Sea. J Oceanogr 75:257-271. https://doi.org/10.1007/s10872-018-0497-6

Kim YH, Kim Y-B, Kim K, Chang K-I, Lyu SJ, Cho Y-K, Teague WJ (2006) Seasonal variation of the Korea strait bottom cold water and its relation to the bottom current. Geophys Res Lett 33:L24604. https://doi.org/10.1029/2006GL027625

Kodama T, Morimoto H, Igeta Y, Ichikawa T (2015) Macroscalewide nutrient inversions in the subpolar layer of the Japan Sea during summer. J Geophys Res 120:7476-7492. https://doi. org/10.1002/2015JC010845

Kodama T, Igeta Y, Kuga M, Abe S (2016) Long-term decrease in phosphate concentrations in the surface layer of the southern Japan Sea. J Geophys Res 121:7845-7856. https://doi. org/10.1002/2016JC012168

Koslow JA, Goericke R, Lara-Lopez A, Watson W (2011) Impact of declining intermediate-water oxygen on deepwater fishes in the California Current. Mar Ecol Prog Ser 436:207-218. https://doi. org/10.3354/meps09270

Koslow JA, Miller EF, McGowan JA (2015) Dramatic declines in coastal and oceanic fish communities off California. Mar Ecol Prog Ser 538:221-227. https://doi.org/10.3354/meps11444

Minami H, Kano Y, Ogawa K (1999) Long-term variations of potential temperature and dissolved oxygen of the Japan Sea Proper Water. J Oceanogr 55:197-205

Minobe S, Sako A, Nakamura M (2004) Interannual to interdecadal variability in the Japan Sea based on a new gridded upper water temperature dataset. J Phys Oceanogr 34:2382-2397. https://doi. org/10.1175/JPO2627.1 
Nakada S, Hirose N (2009) Seasonal upwelling underneath the Tsushima Warm Current along the Japanese shelf slope. J Mar Sys 78:206-213. https://doi.org/10.1016/j.jmarsys.2009.02.015

Nishimura S (1966) The zoogeographical aspects of the Japan Sea. PartIII. Pub Seto Mar Biol Lab 13:365-384

Nishimura S (1968) The zoogeographical aspects of the Japan Sea. PartIV. Pub Seto Mar Biol Lab 15:329-352

Onitsuka G, Yanagi T, Yoon H-J (2007) A numerical study on nutrient sources in the surface layer of the Japan Sea using a coupled physical-ecosystem model. J Geophys Res 112:C05042. https:// doi.org/10.1029/2006JC003981

Oschlies A, Brandt P, Stramma L, Schmidtko S (2018) Drivers and mechanisms of ocean deoxygenation. Nat Geosci 11:467-473. https://doi.org/10.1038/s41561-018-0152-2

Qian W, Dai M, Xu M, Kao S-J, Du C, Liu J, Wang H, Guo L, Wang L (2017) Non-local drivers of the summer hypoxia in the East China Sea off the Changjiang Estuary. Estuar Coast Shelf Sci 198:393-399. https://doi.org/10.1016/j.ecss.2016.08.032

Remen M, Oppedal F, Torgersen T, Imsland AK, Olsen RE (2012) Effects of cyclic environmental hypoxia on physiology and feed intake of post-smolt Atlantic salmon: Initial responses and acclimation. Aquacult 326-329:148-155. https://doi.org/10.1016/j. aquaculture.2011.11.036

Sasano D, Takatani Y, Kosugi N, Nakano T, Midorikawa T, Ishii M (2015) Multidecadal trends of oxygen and their controlling factors in the western North Pacific. Glob Biogeochem Cy 29:935-956. https://doi.org/10.1002/2014GB005065

Sasano D, Takatani Y, Kosugi N, Nakano T, Midorikawa T, Ishii M (2018) Decline and bidecadal oscillations of dissolved oxygen in the Oyashio region and their propagation to the western North Pacific. Glob Biogeochem Cycl 32:909-931. https://doi. org/10.1029/2017GB005876

Schmidtko S, Stramma L, Visbeck M (2017) Decline in global oceanic oxygen content during the past five decades. Nature 542:335-339. https://doi.org/10.1038/nature21399

Schlitzer R (2013) Ocean Data View Ver. 4.5.7. https://odv.awi.de.

Senjyu T (1999) The Japan Sea Intermediate Water; its characteristics and circulation. J Oceanogr 55:111-122

Stramma L, Schmidtko S, Levin LA, Johnson GC (2010) Ocean oxygen minima expansions and their biological impacts. Deep-Sea Res I 57:587-595. https://doi.org/10.1016/j.dsr.2010.01.005

Stramma L, Prince ED, Schmidtko S, Luo J, Hooliham JP, Visbeck M, Wallace DWR, Brandt P, Kortzinger A (2011) Expansion of oxygen minimum zones may reduce available habitat for tropical pelagic fishes. Nat Clim Change 2:33-37. https://doi.org/10.1038/ NCLIMATE1304

Stramma L, Oschlies A, Schmidtko S (2012) Mismatch between observed and modeled trends in dissolved upper-ocean oxygen over the last 50 yr. Biogeosci 9:4045-4057. https://doi. org/10.5194/bg-9-4045-2012

Stramma L, Schmidtko S, Bograd SJ, Ono T, Ross T, Sasano D, Whitney FA (2020) Trends and decadal oscillations of oxygen and nutrients at 50 to $300 \mathrm{~m}$ depth in the equatorial and North Pacific. Biogeosci 17:813-831. https://doi.org/10.5194/bg-17-813-2020

Takikawa T, Yoon J-H, Cho K-D (1995) The Tsushima Warm Current through Tsushima Straits estimated from ferryboat ADCP Data. J Phys Oceanogr 35:1154-1168. https://doi.org/10.1175/JPO2742.1
Talley LD, Lovanov V, Ponomarev V, Salyuk A, Tishchenko P, Zhabin I, Riser S (2003) Deep convection and brine rejection in the Japan Sea. Geophys Res Lett 30:1159. https://doi.org/10.1029/2002G L016451

Teague WJ, Jacobs HT, Perkins HT, Book JW, Chang K-I, Suk M-S (2002) Low-frequency current observations in the Korea/ Tsushima Strait. J Phys Oceanogr 32:1621-1641. https://doi. org/10.1175/1520-0485(2002)032\%3c1621:LFCOIT\%3e2.0.CO;2

Tsunogai S, Kawada K, Watanabe S, Aramaki T (2003) CFC indicating renewal of the Japan Sea deep water in winter 2000-2001. J Oceanogr 59:685-693

Rabalais NN, Diaz RJ, Turner RE, Gilbert D, Zhang J (2010) Dynamics and distribution of natural and human-caused hypoxia. Biogeosci 7:585-619. https://doi.org/10.5194/bg-7-585-2010

Vaquer-Sunyer R, Duarte CM (2008) Thresholds of hypoxia for marine biodiversity. Proc Natl Ac Sci 105:15452-15457

Wada Y, Yamada H (1997) Flow patterns in Wakasa Bay, Japan Sea. Bull Japan Sea Natl Fish Res Inst 47:1-12 ((in Japanese with English abstract))

Wang H, Dai M, Liu J, Kao S-J, Zhang C, Cai W-J, Wang G, Qian W, Zhao M, Sun Z (2016) Eutrophication-driven hypoxia in the East China Sea off the Changiiang Estuary. Environ Sci Tech 50:22552263. https://doi.org/10.1021/acs.est.5b06211

Wang H, Jiang L-Q, Carter BR, Cai W-J (2020) Year of emergence of ocean acidification in the global ocean. ESSOAr. https://doi. org/10.1002/essoar.10502274.1

Watanabe T, Katoh O, Yamada H (2006) Structure of the Tsushima warm current in the north-eastern Japan Sea. J Oceanogr 62:527538. https://doi.org/10.1007/s10872-006-0073-3

Watanabe T, Shimizu D, Nishiuchi K, Hasegawa T, Katoh O (2009) Surface current structure of the Tsushima Warm Current region in the Japan Sea derived by satellite-tracked surface drifters. J Oceanogr 65:791-801. https://doi.org/10.1007/s1087 2-009-0066-0

Watanabe YW, Wakita M, Maeda N, Ono T, Gamo T (2003) Synchronous bidecadal periodic changes of oxygen, phosphate and temperature between the Japan Sea deep water and the North Pacific intermediate water. Geophys Res Lett 30:2273. https:// doi.org/10.1029/2003GL018338

Wei Q, Yao Q, Wang B, Xue L, Fu M, Sun J, Liu X, Yu Z (2019) Deoxygenation and its controls in a semienclosed shelf ecosystem, northern Yellow Sea. J Geophys Res 124:9004-9019. https://doi. org/10.1029/2019JC015399

Weiss RF (1970) The solubility of nitrogen, oxygen and argon in water and seawater. Deep-Sea Res 16:321-322. https://doi. org/10.1016/0011-7471(70)90037-9

Whitney F, Bograd S, Ono T (2013) Nutrient enrichment of the subarctic Pacific Ocean pycnocline. Geophys Res Lett 40:2200-2205. https://doi.org/10.1002/grl.50439

Zhang J, Gilbert D, Gooday AJ, Naqvi SWA, Middelburg JJ, Scranton M, Ekau W, Pena A, Dewitte B, Oguz T, Monteiro PMS, Urban E, Rabalais NN, Ittekkot V, Kemp WM (2010) Natural and human-induced hypoxia and consequences for coastal areas: synthesis and future development. Biogeosci 7:1443-1467. https ://doi.org/10.5194/bg-7-1443-2010 